\title{
Calcium Imaging of Rhythmic Network Activity in the Developing Spinal Cord of the Chick Embryo
}

\author{
Michael O'Donovan, Stephen Ho, and Wayne Yee \\ Section on Developmental Neurobiology, Laboratory of Neural Control, NINDS, NIH, Bethesda, Maryland 20892
}

\begin{abstract}
Video-rate imaging of spinal neurons loaded with calciumsensitive dyes was used to investigate the calcium dynamics and cellular organization of spontaneously active rhythmgenerating networks in the spinal cord of E9-E12 chick embryos. Spinal neurons were loaded with bath-applied fura2am. Motoneurons were also loaded by retrograde labeling with dextran-conjugated, calcium-sensitive dyes. Dye-filled motoneurons exhibited large fluorescent changes during antidromic stimulation of motor nerves, and an increase in the $340 / 380$ fura fluorescence ratio that is indicative of increased intracellular free calcium. Rhythmic fluorescence changes in phase with motoneuron electrical activity were recorded from motoneurons and interneurons during episodes of evoked or spontaneous rhythmic motor activity. Fluorescent responses were present in the cytosol and in the perinuclear region, during antidromic stimulation and network-driven rhythmic activity.

Optically active cells were mapped during rhythmic activ-
\end{abstract} ity, revealing a widespread distribution in the transverse and horizontal planes of the spinal cord with the highest proportion in the ventrolateral part of the cord. Fluorescent signals were synchronized in different regions of the cord and were similar in time course in the lateral motor column and in the intermediate region. In the dorsal region the rhythm was less pronounced and the signal decayed after a large initial transient. Video-rate fluorescent measurements from individual cells confirmed that fluorescent signals were synchronized in interneurons and in motoneurons although the time course of the signal could vary between cells. Some of the interneurons exhibited tonic elevations of fluorescence for the duration of the episode whereas others were rhythmically active in phase with motoneurons. At the onset of each cycle of rhythmic activity the earliest fluorescent change occurred ventrolaterally, in and around the lateral motor column, from which it spread to the rest of the cord.

The results suggest that neurons in the ventrolateral part of the spinal cord are important for rhythmogenesis and that axons traveling in the ventrolateral white matter may be Involved in the rhythmic excitation of motoneurons and interneurons. The widespread synchrony of the rhythmic calcium transients may reflect the existence of extensive excitatory

\footnotetext{
Received July 20, 1993; revised Apr. 6, 1994; accepted Apr. 21, 1994.

Thanks are due to George Dold for constructing some of the optical equipment used in this study and to Dr. Robert Burke for his criticism of the manuscript.

Correspondence should be addressed to Michael O'Donovan, Section on Developmental Neurobiology, Laboratory of Neural Control, NINDS, NIH, Bethesda, MD 20892.

Copyright (C) 1994 Society for Neuroscience $0270-6474 / 94 / 146354-16 \$ 05.00 / 0$
}

interconnections between spinal neurons. The network-driven calcium elevations in the cytosol and the perinuclear region may be important in mediating activity-dependent effects on the development of spinal neurons and networks.

[Key words: calcium imaging, spinal, motoneurons, rhythmic activity, development]

Spontaneous neural activity is a characteristic feature of the developing spinal cord that has been proposed to play an important role in neural (Pittman and Oppenheim, 1978, 1979; Garner et al., 1992; Mendelson, 1992) and muscle development (Renaud et al., 1978; Toutant et al., 1979; McLennan, 1983). The chick embryo is spontaneously active for most of its development in episodes of recurring motor activity that begin at E3-E4 and persist until hatching (Hamburger and Balaban, 1963; Alconero, 1965; Bekoff et al., 1975; Bekoff, 1976). At present, the mechanisms responsible for this behavior are not clear and the role of spontaneous activity during development is incompletely understood. Intracellular and whole-cell recordings from the isolated spinal cord have shown that motoneurons receive rhythmic inhibitory and excitatory synaptic inputs ( $\mathrm{O}^{\prime}$ Donovan, 1989; Sernagor and O'Donovan, 1991) that arise from premotor interneurons. Recent lesion experiments have revealed that the ventrolateral part of the lumbosacral cord generates rhythmic alternation of antagonist motoneurons, suggesting that cells in this region may be important for the genesis of this behavior (Ho and O'Donovan, 1993). However, further progress in understanding the origins of embryonic motility requires the identification, location and activation patterns of the active cells as well as elucidation of their connections and membrane properties. As a first stage in attaining this goal we have developed methods for imaging the activity of the rhythmically active networks in the developing spinal cord. This has been accomplished by digital video microscopy of spinal neurons loaded with fluorescent calcium dyes to monitor the changes in intracellular free calcium that accompany rhythmic neural activity. The ability of this technique to resolve the calcium transients of individual cells has allowed us to record the activity patterns and location of spinal neurons activated during episodes of rhythmic activity.

A preliminary account of this work has been published in abstract form (O'Donovan et al., 1990, 1991) and has been discussed in a recent review (O'Donovan et al., 1992).

\section{Materials and Methods}

Isolated spinal cord preparation. All experiments were performed using an isolated preparation of the spinal cord that has been described in detail previously (O’Donovan and Landmesser, 1987; O'Donovan, 1989). 
White Leghorn chick embryos were rapidly decapitated, eviscerated under Tyrode's solution, either cooled $\left(10-15^{\circ} \mathrm{C}\right)$ or at room temperature $\left(18-22^{\circ} \mathrm{C}\right)$. Muscle nerves or ventral roots were dissected free for recording and stimulation and the spinal cord was removed from the vertebral column and pinned out in a Sylgard lined perfusion chamber.

Dye loading. Spinal neurons were loaded in the dark using one of two methods. In the first method cells were loaded with the membranepermeant fura-2am that was bath applied to the cut surface of the spinal cord. A $10 \mu \mathrm{M}$ solution of fura-2am in Tyrode's solution was made by adding $1 \mathrm{mg}$ of fura-2am (Molecular Probes) to $100 \mu \mathrm{l}$ of DMSO that contained Pluronic $(0.0025 \mathrm{gm} / \mathrm{ml})$. This solution was then added to $100 \mathrm{ml}$ of Tyrode's solution and sonicated for 10-20 min. The cord was loaded for $1 \mathrm{hr}$ with this solution, and then washed for a further hour before recordings were taken. In most experiments the spinal cord was cut transversely between LS3 and LS4. Initially, the cuts were made with scissors, but in later experiments they were made using a vibrating piece of razor blade attached to a micromanipulator. The assembly could be slowly advanced into the perfusion chamber under direct visual control to make the cuts. In some experiments the cord was cut horizontally using a vibrating needle mounted on a micromanipulator (Ho and O'Donovan, 1993).

In the second loading method motoneurons were filled retrogradely with calcium-sensitive dyes conjugated to dextran (O'Donovan et al., 1993). These included calcium green and fura- 2 conjugated to dextran (Molecular Probes). A $25-50 \% \mathrm{w} / \mathrm{v}(25-50 \mathrm{~mm})$ solution of the dye in Tyrode's solution containing $2.5 \%$ Triton X-100 was microinjected extracellularly into muscle nerves or the ventral roots. The dye was injected, using mouth or compressed air pressure, through a glass micropipette. Usually, the perfusion flow in the chamber was set up to wash excess dye away from the preparation, and in some experiments the perfusion medium was not recirculated during the injection. The spinal cord was then superfused with Tyrode's solution for 6-24 hr, at room temperature to allow sufficient time for transport and loading.

In the majority of experiments the cord was viewed using an inverted microscope (Nikon Diaphot). For this purpose the dye-loaded cord was placed within a perfusion chamber fixed to the stage of the microscope. A coverslip formed the base of this chamber onto which the cut face of the cord was gently pressed. This arrangement proved inconvenient because access to the roots or nerves near the cut face was limited. For this reason we developed a horizontally mounted microscope (see Fig. $1 A$ ) to view the cord. With this arrangement the cord was pinned to a moveable platform inside the perfusion chamber (Fig. $1 B$ ). The platform was mounted on a micromanipulator so that the cut face of the cord could be gently pressed onto a coverslip forming one side of the perfusion chamber. The perfusion chamber and micromanipulator were mounted on a motorized stage that was used for focusing.

Fura-loaded cells were excited at 380,360 , or $340 \mathrm{~nm}$ (interference filters, Melles Griot) using a $75 \mathrm{~W}$ xenon lamp. Activity-dependent changes in fluorescence above $510 \mathrm{~nm}$ (Barrier filter, Nikon) were detected using an intensified CCD camera (Videoscope KS1381 coupled to Pulnix TM-845). Motoneurons retrogradely loaded with calcium green dextran were viewed with standard fluorescein filters. Video signals were stored on 1/2 inch or 3/4 inch videotape (Panasonic AG-1960 or Panasonic NV-9240XD) for later analysis. The output of the camera was also fed to an 8-bit frame grabber and a 16-bit coprocessor (Data Translation DT-2861 and DT-2858) in an AT-compatible computer. To obtain signals at video rates ( $30 \mathrm{frames} / \mathrm{sec}$ ), the cord was excited at a single wavelength that precluded determination of absolute calcium levels but allowed fractional changes in fluorescence to be calculated. Video-rate imaging of the decreased fluorescence accompanying intracellular calcium elevation in fura-loaded cells illuminated at $380 \mathrm{~nm}$ was accomplished by inverting the incoming video data and subtracting each frame in real time from an inverted control image (no activity) using the on-board arithmetic and logic unit of the frame grabber. This resulted in a positive difference image in which brightness was proportional to the decrease in fluorescence. The images were usually displayed in false color and were expanded to occupy the full range $(0-255)$ of the frame store.

Quantification of fluorescence changes. To quantify the changes in fluorescence the video data were transferred onto an optical disk (Panasonic TQ-3031F). The fluorescence in selected cells or regions was measured by digitizing individual frames from the disk and then averaging the pixels within a particular cell or region. Local background subtraction was performed on individual cells because the neuropil behind the cells exhibited transients of fluorescence during rhythmic activity that sometimes differed from those of the cell being analyzed.
A static background subtraction would not have addressed this problem because the fluorescence under the cells of interest, and therefore the background, was changing during activity. The subtraction was accomplished by averaging the pixel values in a doughnut-shaped region around each cell in every video frame and then subtracting the resulting time series from a similar series in which the measurements had been made within the cell's boundary. The primary purpose of the background subtraction was to eliminate the contribution of light from cells lying under the cell of interest thereby preserving the fidelity of the time course of the fluorescence signals in individual cells. There are, however, several limitations with this method that might result in errors in the estimation of the amplitude of the fluorescence transients. First, the method assumes that the fluorescence in the region immediately surrounding the cell is similar to that underlying the cell. While this is likely to be true in the great majority of cases, departures from this condition could lead to errors in the estimate of the size of the transient. One manifestation of this error was that some of the fura-loaded cells $(<5 \%)$ exhibited fractional changes of fluorescence $>100 \%$ during rhythmic activity. Rejected cells were often poorly labeled with low fluorescence, which made them more sensitive to errors of background subtraction. Another concern of the method is that the background region might contain scattered light from the cell of interest. While subtraction of this scattered light should not alter the time course of the signal it might introduce errors into the amplitude estimate. For the 22 cells illustrated in Figure 12 the background fluorescence, computed on the difference image in Figure $12 \mathrm{~A}$, was about one-third of the cellular fluorescence. Since the background ring almost invariably included rhythmically active, labeled processes and cells other than the cell of interest, it seems likely that the error arising from scattered light is likely to be small.

Time series generated this way were normalized to the resting level of fluorescence and smoothed using a five-point moving average. The maximum amplitude of the fluorescence change was determined after averaging several adjacent values at the peak of the signal. For rhythmic signals three to five frames were averaged and for antidromic signals, which remained stable for longer periods, a section of 2-9 sec was averaged to obtain a reliable estimate of the maximum change. Mean values are presented \pm 1 SD unless otherwise noted.

Linearity of recording system. We measured the linearity of our re cording system in the following manner. A fluorescent plastic block was placed on the stage of the inverted Nikon Diaphot microscope. The block was illuminated at different intensities by placing neutral density filters in the excitation light path. The emitted light was split in a multiimage module so that $50 \%$ was directed toward a linear photomultiplier and $50 \%$ toward the intensified video camera. The output of the camera was recorded onto videotape. The tape recorder (Panasonic NV$9240 \mathrm{XD}$ ) was placed in the manual gain mode, and the emitted light level adjusted so that the brightest pixels in the image reached a level of 255 . The intensity of the excitation light was then varied by placing neutral density filters in the excitation light path and the resulting fluorescence was measured by the photomultiplier and the video images from the camera were recorded onto videotape. The tape recorded data were then replayed and the fluorescence resulting from each excitation level was digitized by the frame grabber. The intensity of the fluorescence was measured and plotted against the excitation intensity and the measured output from the photomultiplier. Both of these measures showed that the system was linear over the range of light levels employed in these experiments (Fig. 1C).

Number and distribution of active cells. The number of cells activated during rhythmic activity was determined by the following method. First a difference image was obtained by subtracting a control image from an image averaged during a period of rhythmic activity. Each image was generally the average of 30 frames. This difference image was smoothed using a $5 \times 5 \mathrm{kernel}$, and then thresholded. The threshold was determined for each difference image by measuring the mean and standard deviation of the fluorescence over the spinal cord in a control image (no activity). These statistics provided a measure of the baseline noise in the image. Cells were identified as contiguous clusters of pixels whose area exceeded nine square pixels and in which the fluorescence exceeded the noise level by 6 SDs.

Recording and stimulation of motoneurons. Motoneuron electrical activity was recorded from muscle nerves or ventral roots using suction electrodes connected to a high-gain DC amplifier (World Precision Instruments DAM-70). Signals were amplified $(1000-10,000 \times)$ with a bandwidth of $\mathrm{DC}$ to 1 or $3 \mathrm{kHz}$ and stored on magnetic tape for later analysis (Neurodata DR-886). The electrical signals were also recorded on one of the audio tracks of the videotape recorder to allow synchro- 

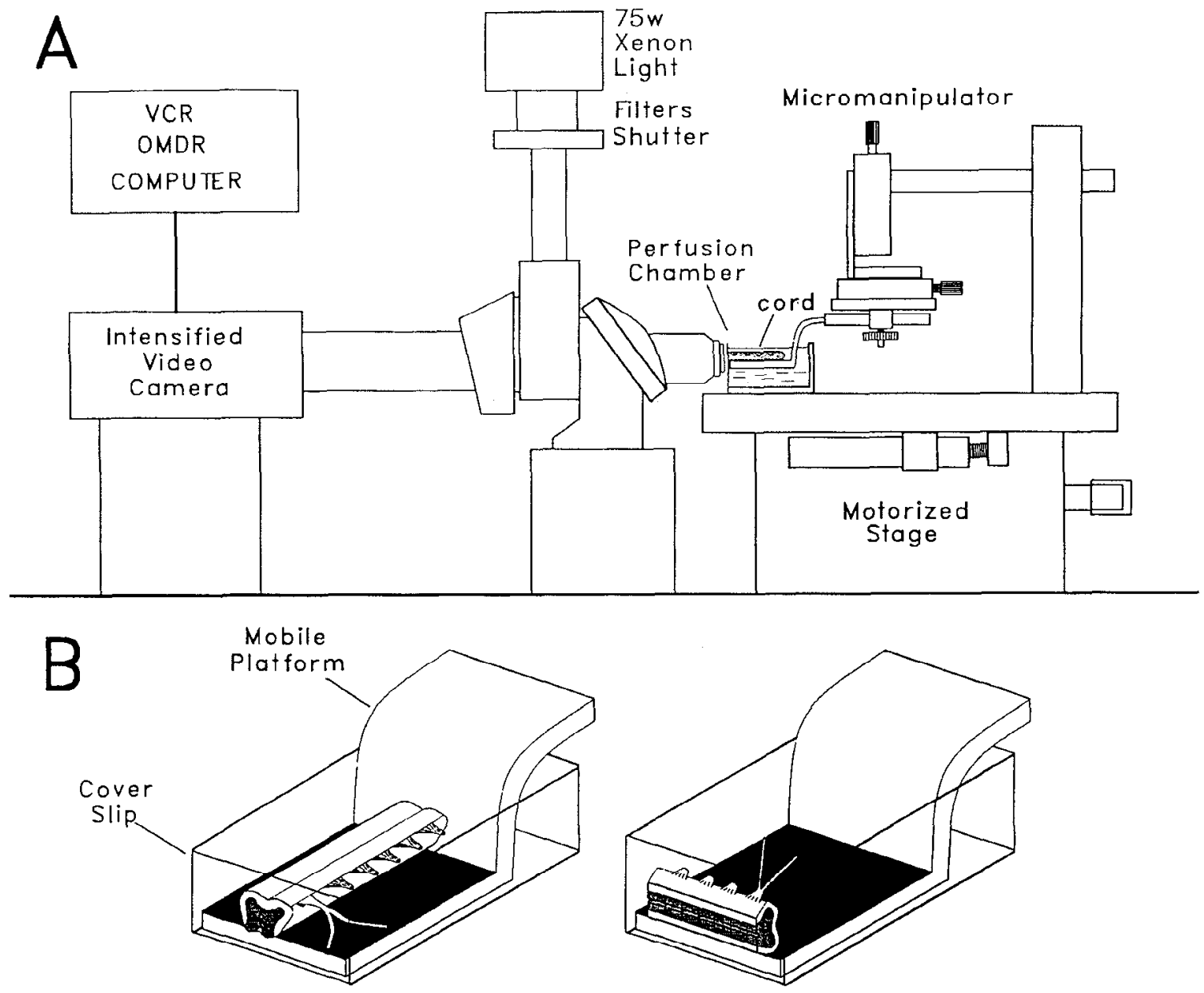

C
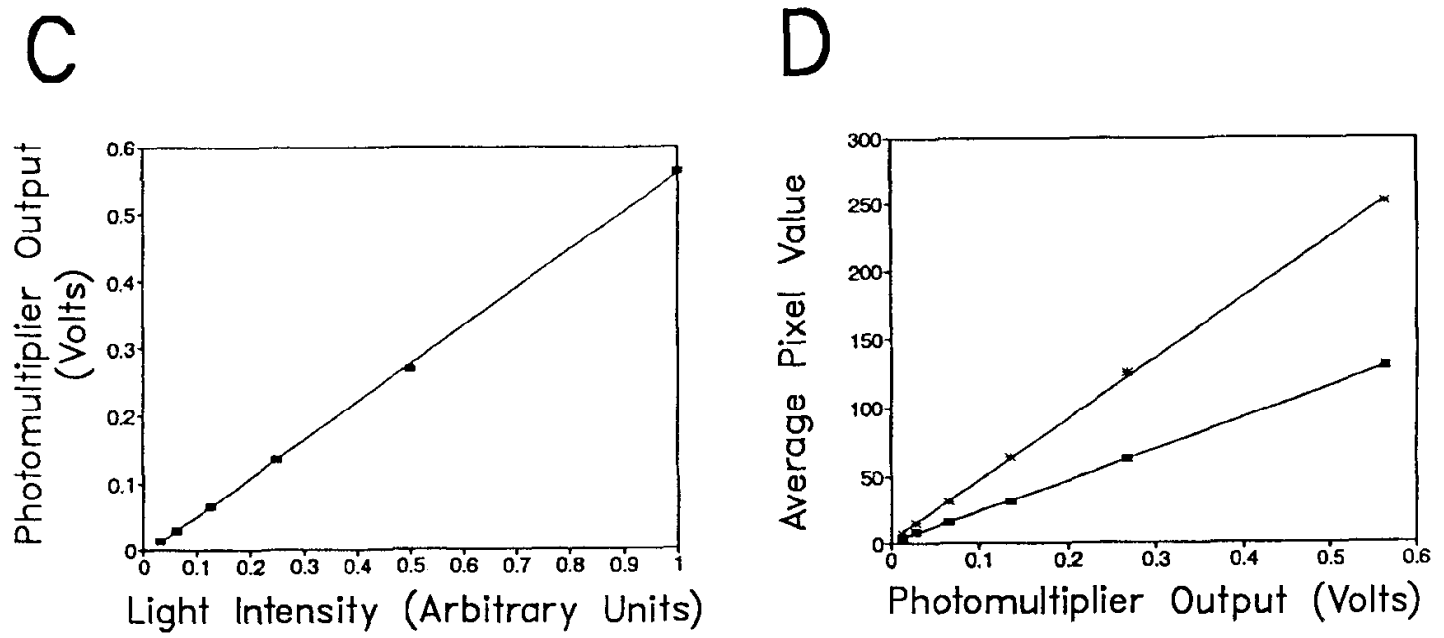

Figure 1. $A$ and $B$, Experimental arrangement for recording fluorescence changes in the spinal cord during motor activity using a horizontally mounted microscope. The spinal cord was cut either transversely or horizontally $(B)$ and mounted in a perfusion chamber on a three-dimensional stage. $C$ and $D$, Graphs showing the linearity of the video recording system; see Materials and Methods for details. $C$, Plot of the excitation light intensity against the output of a photomultiplier. The light intensity was derived from the light transmission of neutral density filters placed in the excitation light path. $D$, Plot of photomultiplier output against the average pixel value of the video image played back and digitized from the videotape. The lower slope corresponds to the average pixel value derived from the whole image, whereas the steeper slope was taken from a region of the image in which the pixel values were near the maximum (255) for the 8-bit frame grabber. 
nization with the video data. Motoneurons were also stimulated through the suction electrodes with pulses $0-50 \mu \mathrm{A}, 0.1-0.2 \mathrm{msec}$ of either polarity.

\section{Results}

Appearance of dye-loaded cells

Bath-applied fura-2am. The general appearance of cells in the spinal cord bath-loaded with $10 \mu \mathrm{M}$ fura2-am is illustrated in Figure 2 and Figure 6, $A$ and $D$. Loaded cells were restricted to a narrow 50-100 $\mu \mathrm{m}$ region of the cut face of the spinal cord, and the dye did not appear to fill deeper layers. The reasons for this are not clear but it had the important advantage of reducing the background fluorescence and resulted in labeling of only one or two cell layers. Cellular loading was best in young cords (E8; data not shown) and become progressively less complete in older embryos. In some of the older embryos there was a dorsoventral decline in the intensity of labeling. These observations suggest an age-dependent decline in labeling because the ventral part of the cord is more mature than the dorsal part (Hamburger, 1948,1976 ). Similar findings have been made in mammalian cortex (Yuste and Katz, 1991; Dani et al., 1992). Most of the experiments reported here were made on embryos between E9 and E12 in which some, although not necessarily all, of the LMC motoneurons were loaded successfully and loading of other regions of the cord was uniform (see Fig. 6A,D). The perinuclear region was labeled as well as the cytosol (see Fig. $4 A$ ), but no other obvious compartmentalization of the dye was observed.

Retrogradely labeled motoneurons. Motoneurons were retrogradely filled with dextran-conjugated calcium dyes (fura-2 and calcium green dextran; O'Donovan et al., 1993). Filling resulted in a labeled column of cells restricted to the lateral motor column. This was in contrast to the bath-applied dye that only labeled the surface cells. Retrograde loading had the disadvantage that cellular definition was often poor because so many cells were labeled. However, it had the important benefit that optical signals were derived from an identified population of neurons.

\section{Antidromic responses of motoneurons}

Antidromic stimulation of the ventral roots or a muscle nerve (with the dorsal roots cut) resulted in large changes in the fluorescence of dye-loaded cclls within the confincs of the lateral motor column. Figure $2 B$ shows a difference image obtained by antidromic stimulation of the femorotibialis muscle nerve at 50 $\mathrm{Hz}$. Several cells in a tight cluster were imaged in a location appropriate for femorotibialis motoneurons (Landmesser, 1978). Antidromic responses were also obtained from motoneurons backlabeled with dextran-conjugated dyes as illustrated in Figure 3. In contrast to bath loading with fura-2am, retrogradely filled motoneurons occupied a tight cluster in the location of the lateral motor column (Fig. $3 A, B$ ). Antidromic stimulation of the spinal nerve or ventral root resulted in large signals that could be detected in the cytoplasm and in the perinuclear region (Fig. 3D,E) and an increase in the 340/380 ratio (data not shown; see O'Donovan et al., 1993). The responses to single antidromic shocks could be easily detected in the live video and increased in proportion to the stimulus frequency (Fig. $3 F$; see also O'Donovan et al., 1993).

We were most successful in obtaining antidromic responses from retrogradely loaded motoneurons. This was probably because bath application resulted in fewer labeled motoneurons, and those that were labeled may have had their axons damaged because they were close to the cut surface of the spinal cord. The time course of the fluorescence transient accompanying single antidromic shocks was measured in motoneurons filled with fura-2am $(n=2)$ or backfilled with fura2-dextran $(n=2)$ or calcium green dextran $(n=4)$. The transient peaked within two frames after the stimulus, and it decayed with an approximately exponential time course-based on the linearity of its decline when plotted semilogarithmically. The regression coefficients for the linear fit of the decay curve were greater than 0.93 in seven of eight cells, and was 0.89 in the remaining cell. Fura-filled cells exhibited some variability in their decay time constant (range -159 to $-512 \mathrm{msec}$ ) although the average value of the time constant $(-302 \pm 129 \mathrm{msec}, n=4)$ was similar to that for calcium green-filled cells ( $268 \pm 46 \mathrm{msec}, n=4)$. The peak amplitude of the fluorescent change was slightly higher for calcium green-filled cells $(8.1 \pm 4.2 \%)$ than for fura-filled cells (4.7 $\pm 1.2 \%$ ). During stimulation at higher frequencies the fluorescent responses increased in proportion to the frequency of stimulation. The average fluorescence change for 13 cells filled with bath-applied fura-2am and stimulated at $20 \mathrm{~Hz}$ was 68.6 $\pm 11 \%$.

\section{Fluorescent responses of motoneurons during rhythmic activity}

Motor activity generated by the isolated spinal cord consists of recurring episodes of rhythmic motoneuron bursting (Landmesser and O'Donovan, 1984; O'Donovan, 1989; Ho and O'Donovan, 1993). The cells activated during rhythmic bursting were visualized by subtracting an image acquired during activity from one obtained in the control period just before the onset of activity (Fig. $4 C$ ). Such difference images revealed that calcium accumulated in the both the cytoplasm and the perinuclear region (arrow in Fig. $4 C$ ). This result is consistent with findings from other studies in which depolarization induces calcium elevation in the nucleus (Holliday and Spitzer, 1990; HernandezCruz et al., 1990; Holliday et al., 1991; Birch et al., 1992). Fluorescent changes also occurred in the background neuropil during rhythmic activity and were most evident in normalized images that displayed the fractional change of fluorescence (Fig. $4 D$ ). The background signal presumably arises from fluorescence changes in out-of-focus cells, axons, and dendrites.

The time course of the fluorescence change in motoneurons and its rclation to motoneuron electrical activity is illustrated in Figure 5. During episodes of rhythmic activity the fura-2am signals in motoneurons were tightly coupled to the motoneuron depolarization and discharge recorded from the muscle nerve or the ventral roots (Fig. 5A). Optical signals were not observed in the quiescent periods between episodes of bursting and could not be resolved following blockade of network activity with the excitatory amino acid antagonist kynurenic acid $(n=2)$.

The excitation spectrum of the rhythmic signals in fura-loaded cells (an increase in the 340/380 ratio; Fig. 5A) indicates an increase of intracellular free calcium. Moreover, the small fluorescent changes $(\Delta F / F=-2 \%$ to $-3 \%)$ observed at an excitation wavelength of $360 \mathrm{~nm}$ indicate that noncalcium contributions to the fluorescent signal are likely to be minor.

To ensure that the optical signals recorded from motoneurons arose postsynaptically, rather than from interneuronal processes or terminals on the surface of motoneurons, we recorded from motoneurons retrogradely filled with calcium dyes. During rhythmic activity retrogradely filled motoneurons exhibited rhythmic oscillations of fluorescence in phase with motoneuron 

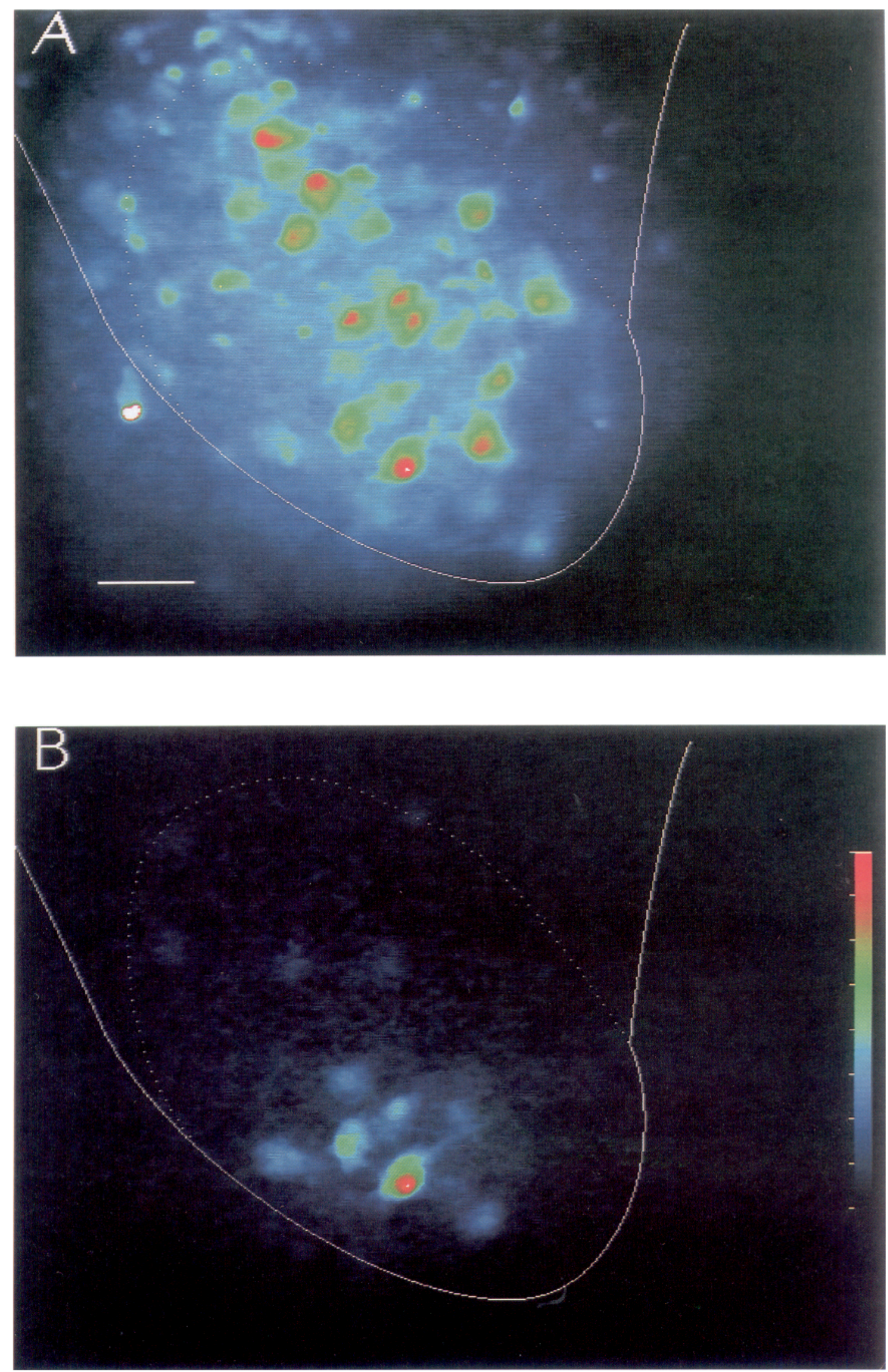
electrical activity (Fig. $5 B$ ). The similarity of these signals to those obtained from cells loaded with membrane-permeant dyes strongly suggests that somatic, optical signals from the bathapplied dye arise postsynaptically.

\section{Distribution of cells activated during network activity}

The ability to image the cells participating in network activity allowed us to map their distribution and dynamics in different regions of the spinal cord. The active cells extended throughout the transverse face of the gray matter and into the dorsal part of the cord (Figs. 6, 7). Fewer active cells were identified in the ventromedial part of the cord (Fig. $6 B, E$ ). Two examples of this type of experiment are shown in Figure 6 . As can be seen from the figure the distribution of active cells cannot simply be explained by regional variations in the number of loaded cells. For instance, cells in the ventromedial region of the cord were well labeled, but very few active cells were found here (Fig. $6 A, B, D, E)$.

Another factor that could influence the observed distribution is the ability of loaded cells to express activity-driven calcium transients. Cells might fail to express such transients if they were damaged, or alternatively, if they did not accumulate significant levels of calcium during neural activity. To assess whether or not inactive cells could generate calcium signals, we depolarized the cord directly with solutions containing elevated $\mathrm{K}^{+}$concentrations (30-50 $\mathrm{mm}$ ). This procedure, performed in three embryos, allowed us to compare maps produced during networkdriven rhythmic activity with those obtained when the spinal cord was directly depolarized with $\mathrm{KCl}$. Two of these experiments are illustrated in Figure 6, which compare the distribution cells produced during rhythmic motor activity (Fig. $6 B, E$ ) and during the tonic firing that accompanies direct depolarization of the cord with solutions containing elevated $\mathrm{KCl}$ (Fig. $6 C, F$ ) In each of these experiments, including one that is not illustrated, $\mathrm{KCl}$ induced widespread activation of neurons coextensive with the distribution of labeled cells. This differed from the distribution of cells activated during rhythmic activity in two ways. First $\mathrm{KCl}$ produced activation of more cells than spontaneous or evoked rhythmic activity and second, areas containing loaded cells that were not activated rhythmically were active during KCl-induced depolarization. This was particularly marked in the ventral region, medial to the lateral motor column.

In tive (E10-E12) embryos we counted the number of rhythmically active cells in different regions of the cord (Fig. 7). Although it would have been desirable to express the number of active cells in any particular region as a fraction of the number of labelled cells, in practice, this was not possible because it was difficult to count unambiguously the overlapping cell profiles. These counts probably underestimate the number of active cells because of the conservative criteria used to define active cells (see Materials and Methods). We found that the lateral half of the cord contained more active cells than the medial part $(80.1 \%$ vs $19.9 \%$, five embryos). In addition, the ventral part contained nearly twice as many cells $(64.7 \%)$ as the dorsal part $(35.3 \%)$.
About $28 \%$ of the active cells were located in the LMC and were presumed to be motoneurons ( 69 of 241 cells in five embryos). Cells within the LMC were significantly larger than those outside the LMC, consistent with their putative identity as motoneurons. Of the remaining cells, which are presumed to be interneurons (see Discussion), most (72.1\%) were located in the lateral half of the cord, and were divided about equally between the dorsal and ventral regions.

The distribution of cells we have just described was obtained in the transverse plane of the spinal cord, generally at the level of LS3. To ensure that the cellular distribution did not simply depend upon the level of section, we also examined the distribution of active cells in horizontal sections of E10-E1 1 embryos in which the dorsal part of the cord was removed down to the level of the central canal (Fig. 8). The dye-labeled region was located just dorsal to the lateral motor column. In such preparations rhythmic activity persists although the number of cycles in each episode can be reduced (Ho and O'Donovan, 1993). During rhythmic activity we found that active cells were distributed along the length of the cord but were concentrated in the lateral two-thirds of the gray matter as would be predicted from the distribution detected in the transverse plane (Fig. 7).

\section{Video-rate mapping of fluorescence changes during rhythmic activity}

The dynamics of the calcium signal in different regions of the cord was further investigated by comparing the calcium transients in $100 \mu \mathrm{m}^{2}$ regions across the cut surface of the spinal cord of E9-E12 embryos (Fig. 9A). These observations revealed that fluorescence transients in different parts of the cord were synchronized during rhythmic activity. The fluorescence transients were similar within the LMC and in the region dorsomedial to the $\mathrm{LMC}$, whereas in the dorsal region the transient decayed after an initial peak and cyclical activity was not as evident as in the more ventral parts of the cord (Fig. 9A,B). Each cycle of fluorescent activity was largely in phase with activity recorded from other regions and with the electrical discharges recorded from the femorotibialis muscle nerve or from a ventral root (Fig. 9B). There were, however, significant differences in onset, the rise time, and the time to peak of the fluorescent signals in the different regions. These differences were most evident at the beginning of an episode of rhythmic activity and are considered in more detail below.

\section{Fluorescence changes at the onset of rhythmic activity}

At the onset of spontaneous or stimulated activity the initial optical activity was frequently observed to begin in the ventrolateral region, often within the lateral motor column. This initial activity consisted of a spatially diffuse fluorescent change that spread medially and dorsally to encompass the whole transverse face of the cord. These findings are shown in Figure 10, which shows the optical activity averaged from the onset of three successive, spontaneously occurring bursts. The first optical activity was detected 1 video frame after the onset of femorotibialis

\section{$\leftarrow$}

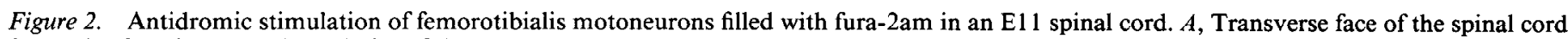

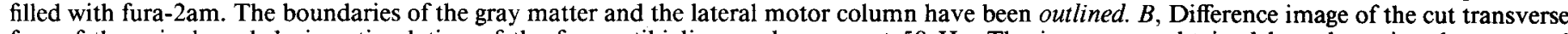

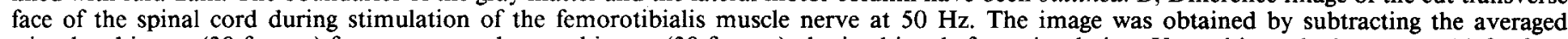

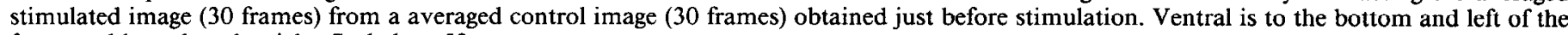
figure and lateral to the right. Scale bar, $50 \mu \mathrm{m}$. 

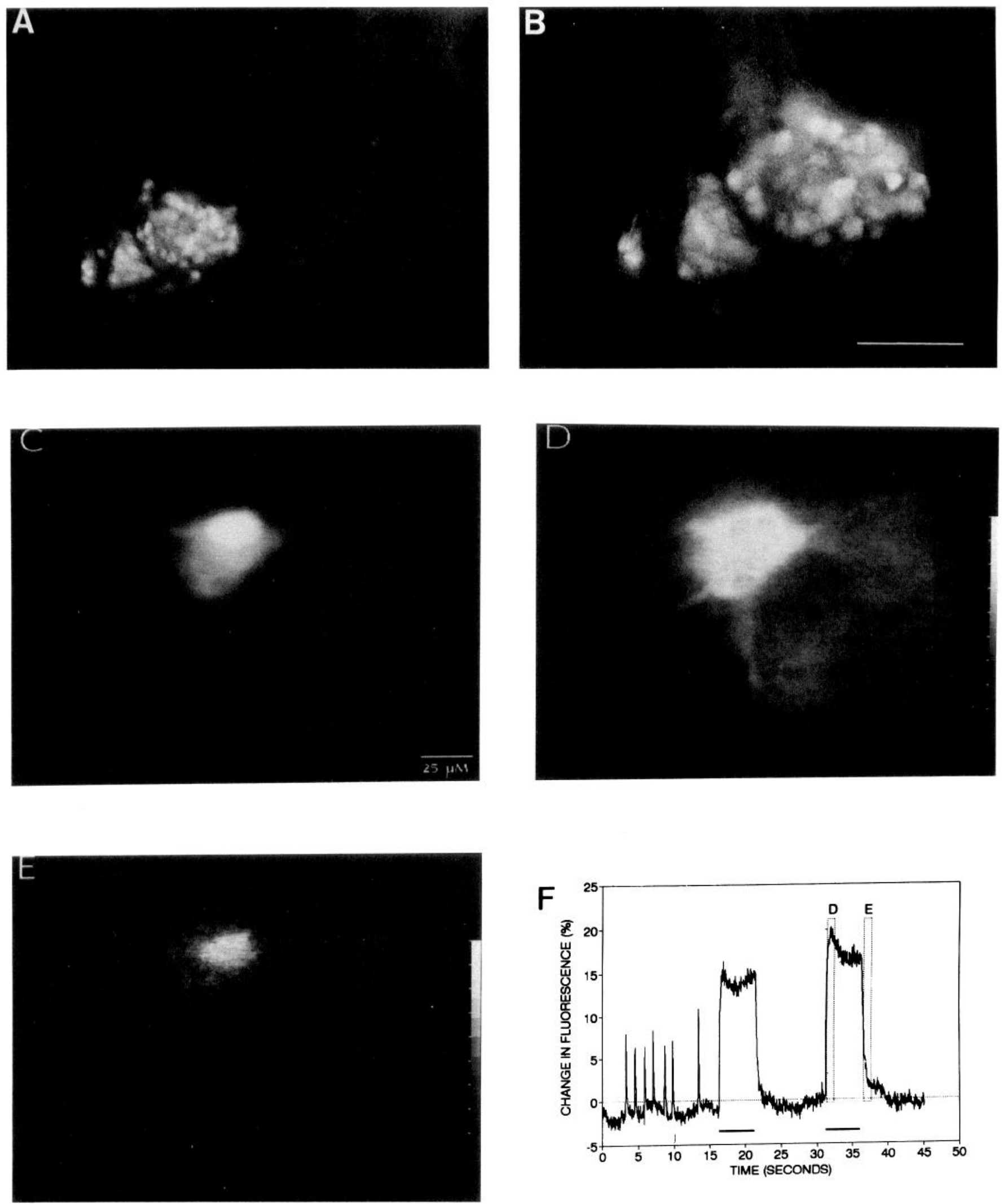

Figure 3. Motoneurons backfilled with fura-2 or calcium green coupled to dextran. $A$ and $B$, Photomicrographs of motoneurons backfilled with fura-2 dextran in a $200 \mu \mathrm{m}$ slice of the spinal cord. $C$, Videomicrograph of a single motoneuron backfilled with calcium green dextran in an E11 spinal cord. $D$, Difference image obtained during antidromic stimulation of the spinal nerve at $50 \mathrm{~Hz}$. The image is the average of 30 frames taken during the period defined by the box labeled $D$ in $F$ at the onset of the train of stimuli. $E$, Difference image obtained during antidromic stimulation of the spinal nerve at $50 \mathrm{~Hz}$ to show the persistence of calcium elevation in the perinuclear region. The image is the average of 30 frames taken during the period defined by the box labeled $E$ in $F$ as the cytosolic signal is decaying. $F$. Measurements of the fluorescence change over the cytosolic region of the motoneuron. The spinal nerve was stimulated antidromically with seven single shocks that were followed by two trains of stimuli at 20 and $50 \mathrm{~Hz}$. The duration of the stimuli is indicated by the bar under each train. 

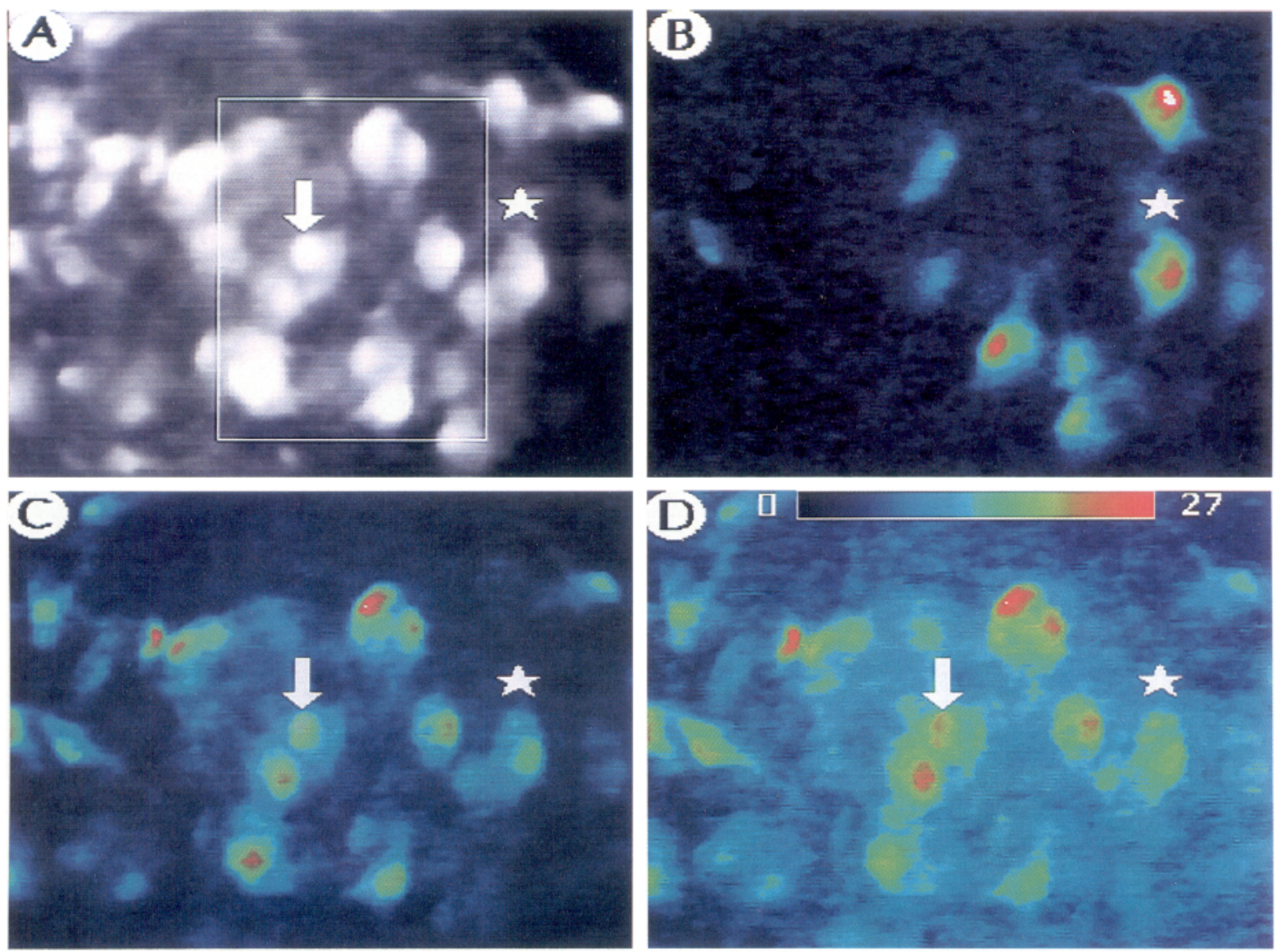

Figure 4. A, Videomicrograph of the lateral motor column region in an E10 lumbosacral spinal cord showing motoneurons loaded with fura2 am. The dye accumulated within the perinuclear region of some cells (arrow). B, Difference image of the region shown in $A$ during antidromic stimulation of the femorotibialis muscle nerve at $20 \mathrm{~Hz}$ reveals the location of motoneuron somata supplying the femorotibialis muscle. The star identifies the same motoneuron in each panel. $C$, Difference image obtained during an episode of evoked rhythmic motor activity reveals the active motoneurons, and shows that an increase in free intracellular calcium accompanies the network driven rhythmic discharges of motoneurons. $D$, Fractional changes of fluorescence were also large in the soma but significant changes in fluorescence occurred in the neuropil consisting of dendrites, axonal processes, and out-of-focus cells. The false color scale in $D$ indicates the percentage change in fluorescence.

electrical activity (frame 1, Fig. 10) and consisted of a spatially diffuse decrease in fluorescence that spread rapidly to cover the whole cord face within a few video frames.

We had not anticipated to find this type of spreading activity, and it suggested the existence of a spatiotemporal pattern of spinal activation that had not been detected before with conventional electrophysiological recordings. For this reason we have quantified the spread of activity in some detail to establish its velocity and consistency between preparations. To accomplish this we compared the timing of peak activity (in the first cycle) in contiguous $100 \mu \mathrm{m}^{2}$ regions of the transverse plane (defined in Fig. 11B). In most experiments (seven of eight), dorsal activity peaked later than that in the LMC (Fig. 11A,C). The progressive increase in the difference between the time to peak activity of the LMC, measured either from the stimulus or from the onset of spontaneous electrical activity, and peak activity in each of the regions is summarized for eight embryos in Figure $11 C$. The average latency to peak activity in the LMC region was $304 \mathrm{msec} \pm 224 \mathrm{msec}$ ( $n=9$ embryos) whereas the latency to peak activity in the dorsal region (region 4 or 5, Fig. $11 B)$ was significantly longer at $489.5 \mathrm{msec}( \pm 205 \mathrm{msec} ; P \leq$ 0.05 , Kolmogorov-Smirnov test). The delayed dorsal activity was not confined to the first cycle and was observed in other cycles within the episode, suggesting it was a phenomenon associated with each cycle rather than episode initiation.

We also measured the time for the initial cycle to reach $50 \%$ of the peak amplitude. This measure was somewhat more sensitive and less subject to noise than the peak measurements and revealed a progressive ventrodorsal increase in the time to $50 \%$ amplitude when referenced to the LMC (Fig. 11D). The time to $50 \%$ amplitude of the fluorescence transient averaged $92 \pm$ $26 \mathrm{msec}$ in the LMC ( $n=9$ embryos), progressively lengthening in the ventrodorsal direction to reach an average value of 178 $\pm 54 \mathrm{msec}(n=9)$ in the dorsal region. The time to $50 \% \mathrm{am}-$ plitude was significantly longer ( $p \leq 0.05$, paired $t$ test) in each of the five regions dorsal to the LMC when compared to the measure in the LMC. From these delays it was possible to construct a plot of the movement of the time to reach $50 \%$ amplitude across the cord face. This was possible because the fluorescence was measured in adjacent regions whose width was $100-140 \mu \mathrm{m}$ (see Fig. 11 legend). In Figure $11 E$ difference in the time to reach $50 \%$ amplitude between each region and the LMC is plotted against the distance from the LMC. This plot shows that the activity spreads across the first three regions at 


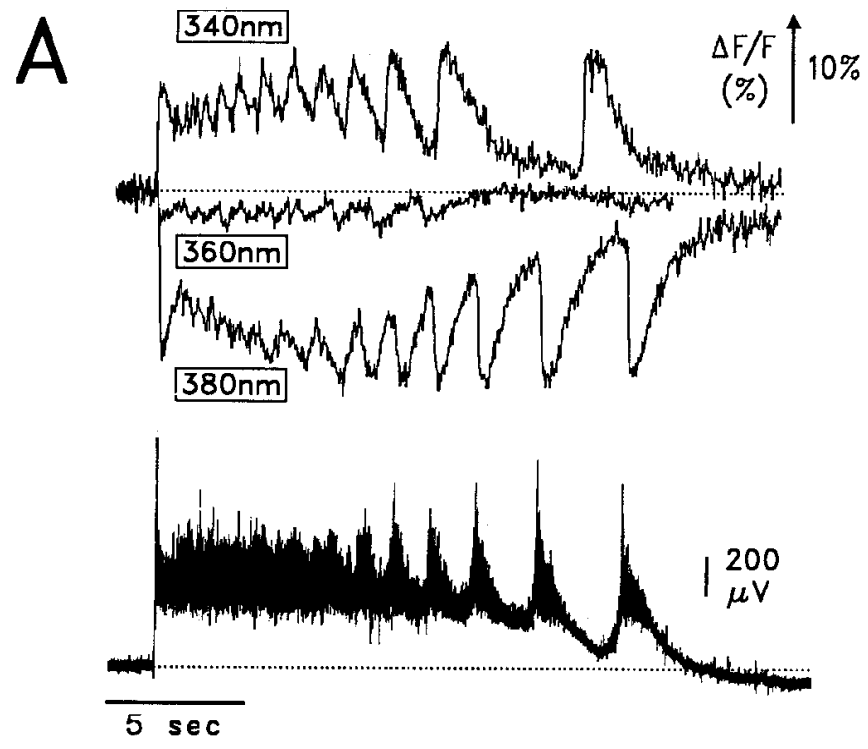

$\mathrm{B}$

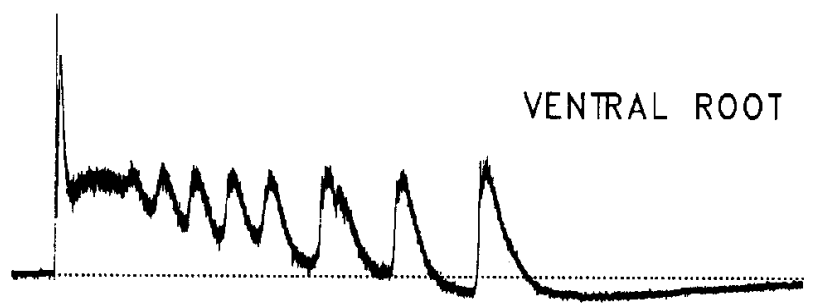

OPTCAL

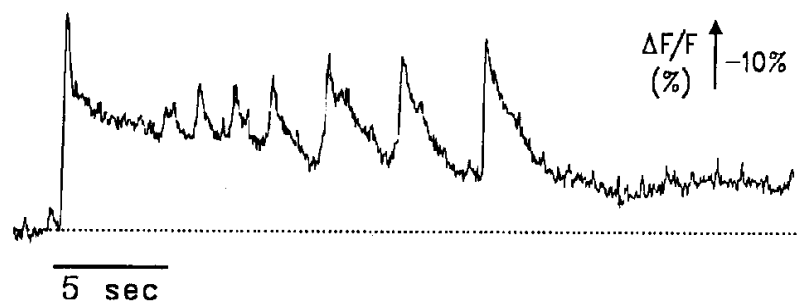

Figure 5. $A$, Fluorescence changes in the lateral motor column averaged over the region outlined in Figure $4 A$ during three episodes of rhythmic motor activity evoked by a single stimulus to the spinal cord of an ElO embryo bath loaded with fura-2am. Each episode was recorded at a different excitation wavelength. The polarity of the responses indicates that the excitation spectrum of the dye-loaded cells changes during rhythmic motor activity from $380 \mathrm{~nm}$ to $340 \mathrm{~nm}$ that is characteristic of the calcium-fura complex. The electrical recordings from the femorotibialis muscle nerve comprise a slow potential on which is superimposed propagated spike activity and were obtained together with the optical trace at $380 \mathrm{~nm}$. $B$, Rhythmic optical signals can also be recorded from motoneurons retrogradely loaded with fura 2 coupled to dextran. The optical signals obtained at an excitation wavelength of 380 $\mathrm{nm}$ are shown together with simultaneously recorded ventral root potentials during an episode of motor activity. Nole that the direction of the fluorescence change has been reversed in this trace and that the fluorescence actually decreases as it does with the bath-applied dye shown in $A$.

approximately $10 \mu \mathrm{m} / \mathrm{msec}$, and invades the most dorsal regions somewhat more slowly with an average velocity of about $4 \mu \mathrm{m}$ / msec.

\section{Fluorescent transients in individual cells}

In addition to the regional measurements we also determined the time course of the fluorescence transients in individual cells after local background subtraction (see Materials and Methods). We were particularly interested in establishing whether or not the fluorescent responses were synchronized in individual cells as they were in the regional measurements (which included contributions from pre- and postsynaptic elements) and also in determining the extent to which the fluorescent signals differed between cells.

Therefore, we made measurements of single cell fuorescence on 137 cells during rhythmic activity in nine embryos. To maximize the signal to noise ratio the measurements were made at a magnification of $20 \times$ in the ventrolateral region. The peak amplitude of the fluorescence change (after local background subtraction) varied widely throughout the population ranging from $14.8 \%$ to $62.5 \%$ (mean $=27.8 \pm 11.7 \%, 137$ cells, nine embryos).

In five motoneurons it was possible to compare the amplitude of the fluorescence transients generated during rhythmic activity with those produced by antidromic activation of the same cells. Such a comparison was possible because the amplitude measurements under the two conditions were made on the same cells, using the identical region for local background subtraction. The only difference in the measurements was the mode of activation. For these five cells the peak fluorescence during evoked rhythmic activity was $26.3 \%$ (range, $16.1-43.9 \%$ ) whereas during antidromic stimulation at $20 \mathrm{~Hz}$ the peak changes averaged $58.5 \%$ for the five cells. Three of the cells were also activated at $5 \mathrm{~Hz}$. For these cells the peak fluorescence change during rhythmic activity was $31.4 \%, 21 \%$, and $16.1 \%$ compared to $22.2 \%, 15.1 \%$, and $13.9 \%$ for $5 \mathrm{~Hz}$ activation. Thus, the calcium transients generated in these cells during rhythmic activity are smaller in amplitude than those resulting from antidromic activation at $20 \mathrm{~Hz}$ and are somewhat larger than those generated during $5 \mathrm{~Hz}$ antidromic trains.

Figure 12 illustrates the fluorescence transients for 22 cells recorded in a single cxpcriment during an episode of rhythmic activity. As can be seen from the figure there was considerable variation in the time course of the fluorescence transients recorded from individual neurons. Cells within the LMC (cells 16-22) are presumed to be motoneurons and show rhythmic oscillations of fluorescence in phase with femorotibialis motoneuron discharge (bottom right panel). Outside the LMC the response of cells was more varied. Some of the cells behaved like motoneurons exhibiting rhythmic oscillations in phase with ventral root or muscle nerve activity (cells 2 and 10) whereas others displayed tonic signals that persisted for the duration of the episode without substantial modulation (cells 6 and 15). Still other cells exhibited a decaying transient after an initial peak (cells 3, 4, and 11). In two cells (14 and 15) we observed an extra cycle of fluorescent activity (starred in Fig. 12) that did not occur in the other cells and was not reflected in the neurogram.

\section{Discussion}

We have shown that calcium imaging can be used to visualize the activity of rhythmically active networks in the developing spinal cord. The technique offers a number of advantages over the use of voltage-sensitive dyes for recording optical neural activity, including low toxicity, large signal size, and cellular resolution. Application of this technique to the developing spinal cord has allowed us to visualize several aspects of network dynamics and organization and has also revealed that network- 

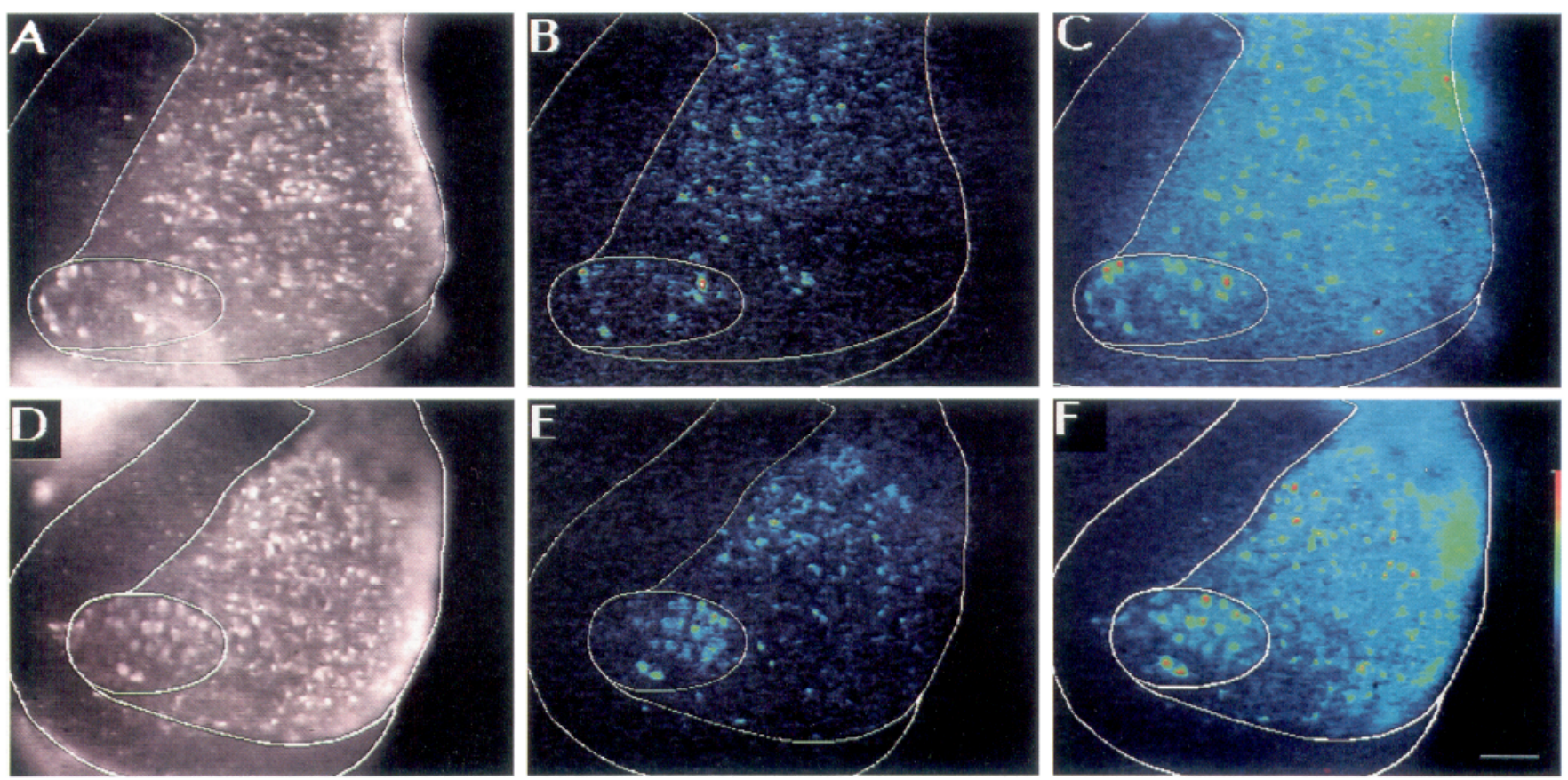

Figure 6. Low-power images of the transverse face of two E11 spinal cords bath loaded with fura-2am. $A$ and $D$, Images of the cut face showing the distribution of loaded cells illuminated at $380 \mathrm{~nm}$. The distribution of cells activated during rhythmic motor activity $(B, E)$ is compared with that obtained during perfusion of the same cords with Tyrode's solution containing $50 \mathrm{~mm} \mathrm{KCl}$ to depolarize cells directly $(C, F)$. The false color images are averages of 30 frames and have each been expanded from 0 to 255 . Dorsal is up and lateral to the left. Scale bar (in $F$ ), $100 \mu \mathrm{m}$ (for $A-F)$.

driven rhythmic activity produces elevations of free intracellular calcium in spinal neurons.

\section{Origin of activity-driven fluorescence transients}

Activity-driven elevations of calcium could arise from several sources, including transmembrane flux and release from intracellular stores. Transmembrane flux could be derived from calcium entry through ligand-gated channels or through voltagesensitive calcium channels. Calcium entry through the NMDA channel has been well documented (MacDermott et al., 1986; Kudo et al., 1991), and several reports have shown calcium entry through non-NMDA receptors can also increase intracellular calcium (Ogura et al., 1990; Hollman et al., 1991). Moreover, GABA application leads to calcium accumulation in mammalian cortical neurons that is probably due to activation of low-voltage-activated calcium channels by the induced depolarization (Yuste and Katz, 1991). During rhythmic activity motoneurons are depolarized by $20-30 \mathrm{mV}$ by a combination of excitatory and inhibitory synaptic potentials (O'Donovan, 1989; Sernagor and O'Donovan, 1991, 1992), so it seems reasonable to assume that calcium entry will accompany this ligand-gated synaptic drive. Another source of transmembrane calcium entry is the activation of voltage-dependent calcium channels during action potentials. Chick motoneurons possess both high- and low-voltage-activated calcium channels (McCobb et al., 1989) that could mediate calcium entry during neuronal discharge. McCobb and Beam (1991) have shown that up to $40 \%$ of the calcium current accompanying the action potential in embryonic chick motoneurons can be derived from low-voltage-activated calcium channels, the remainder coming from high-voltage-activated channels. One further source of intracellular calcium elevation is release from intracellular stores. This mechanism appears to mediate a substantial component
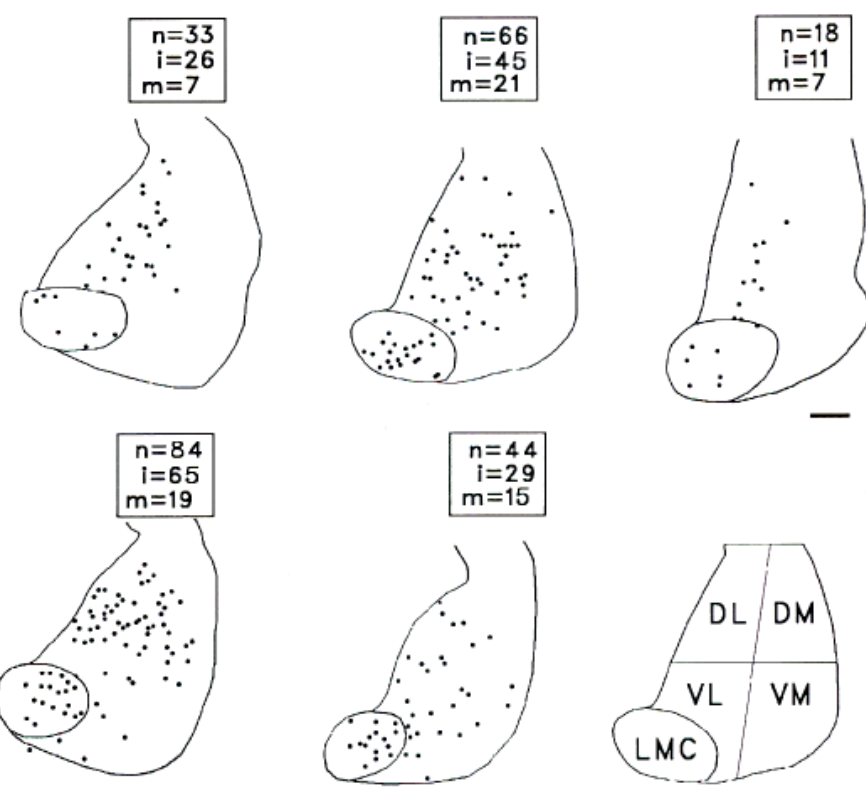

Figure 7. Low-power maps of the cells activated during an episode of evoked or spontaneous rhythmic motor activity. Data are illustrated for five different cords, each of which was loaded with bath-applied fura-2am. The total number of active cells $(n)$, the number within the LMC $(m)$, and the number outside the LMC $(i)$ are indicated above each cord. The bottom right panel indicates the various regions of the cord from which measurements of cell number were performed. $D L$, dorsolateral; $D M$, dorsomedial; $V L$, ventromedial; $V M$, ventromedial. See text for further details. Data are from E10-E12 embryos. Scale bar, $100 \mu \mathrm{m}$ 


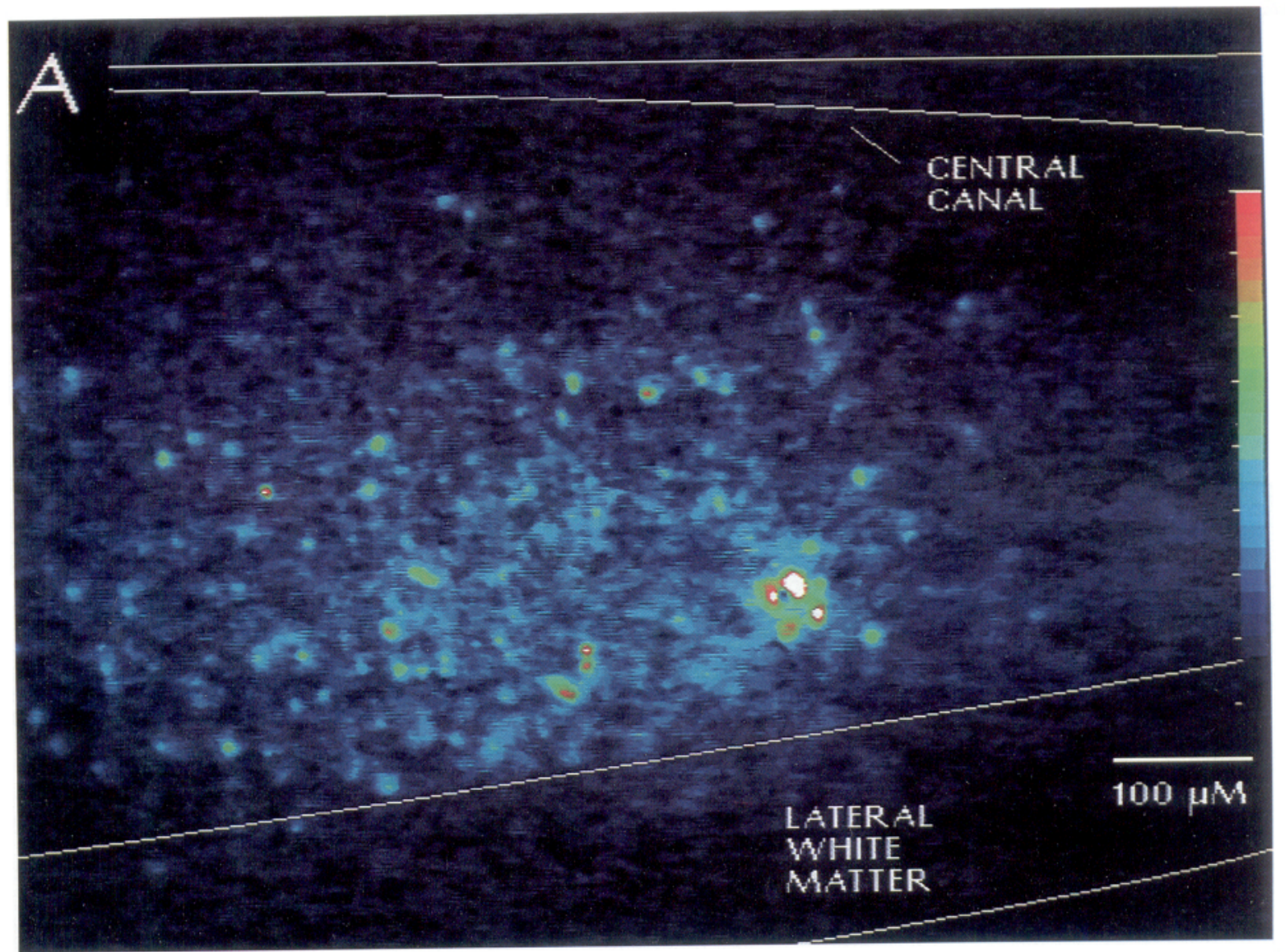

\section{Sciatic Neurogram}

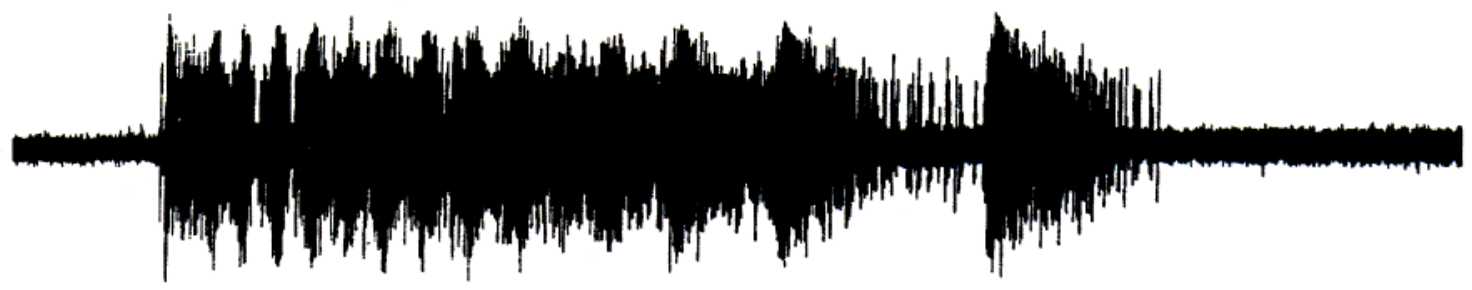

\section{SEC}

Figure 8. Low-power difference image of a horizontal section of an E10 cord showing the distribution of cells activated during an episode of evoked rhythmic activity. The cord was bath loaded with fura2-am and is viewed from the cut dorsal surface. The level of the cut was through the central canal and shows interneurons just dorsal to the lateral motor column. The image is the average of 30 frames taken during the bar under the neurogram of $B$, which shows the electrical recording from the sciatic nerve that was recorded together with the image data.

of the depolarization-dependent increase in calcium of Xenopus embryonic spinal neurons (Holliday et al., 1991).

Although our data do not allow us to identify the relative contribution of different sources to the calcium elevation accompanying rhythmic bursting they do suggest a dominant role for impulse activity. Antidromic stimulation of motoneurons resulted in large fluorescence responses and the transients generated during rhythmic activity were tightly correlated with motoneuron firing. Moreover, the average amplitude of the fluorescence transient generated during rhythmic activity was similar to that produced by antidromic stimulation at $5-10 \mathrm{~Hz}$. Since motoneurons can fire at this rate (O'Donovan, 1989) it suggests that calcium accumulation from other sources is not as prominent as that arising from action potentials.

\section{Distribution and identity of neurons activated during rhythmic activity}

Active cells extended throughout the gray matter with the major concentration in the lateral and ventral regions of the cord. Two possible sources of error could contribute to an underestimate of the number of active cells or to their distribution. First, calcium accumulation in the soma might have been too low to detect with our optical system. This situation could arise if a particular cell received subthreshold synaptic inputs or if the 

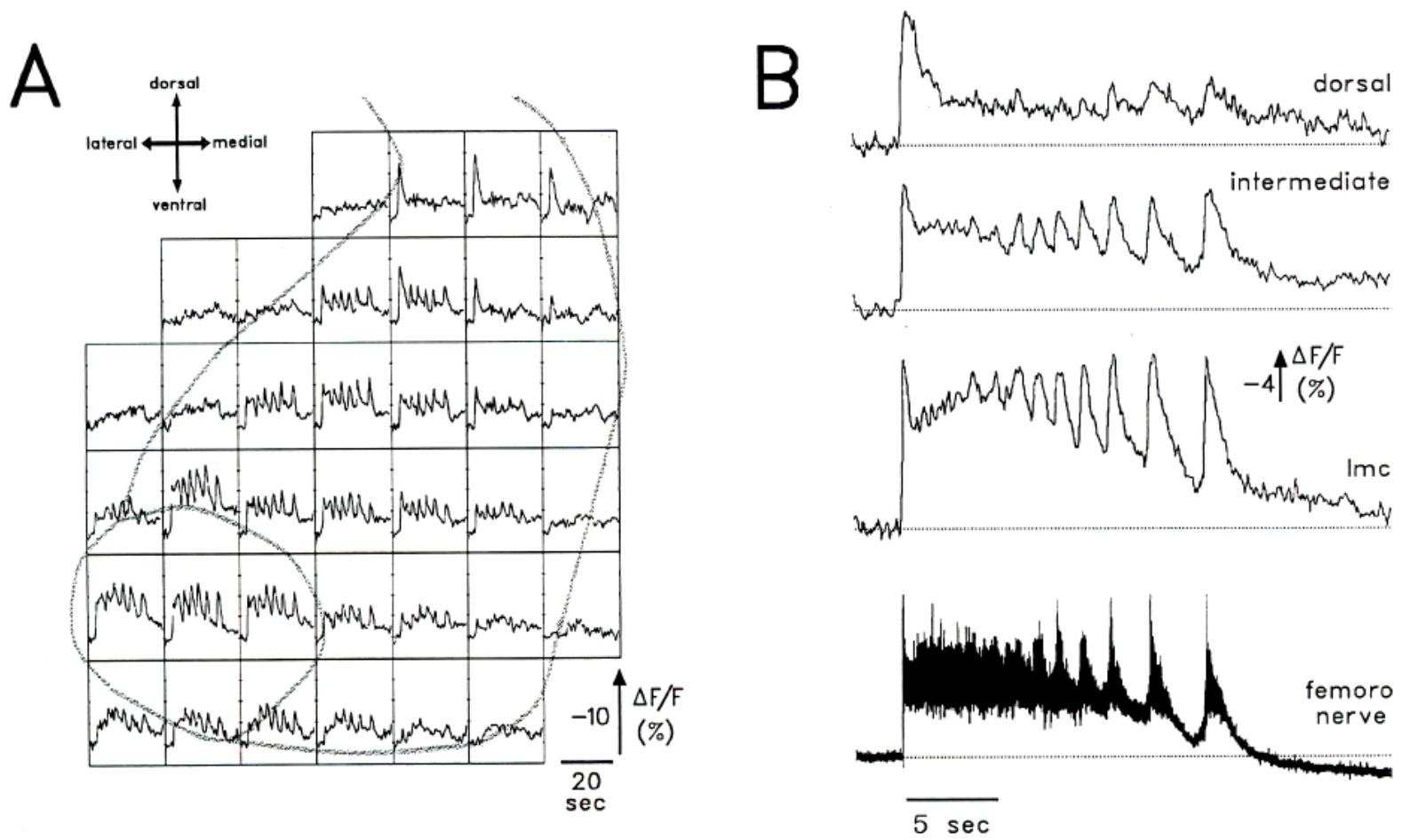

Figure 9. A, Regional differences in the time course of the fluorescence signal accompanying a single episode of rhythmic activity evoked by a single stimulus to the spinal cord. Each region is a $100 \mu \mathrm{m}$ square and the grid is superimposed over the outline of the gray matter. The approximate boundaries of the lateral motor column have also been drawn. All of the pixel values in each region were averaged and plotted for each video frame. The fluorescence changes indicated in each region have been expressed as a fractional change and smoothed using the lowess algorithm. Data are from an E1 1 embryo bath loaded with fura2-am. B, Recordings of optical activity from three regions of an E10 spinal cord. The measurements were made from a grid as shown in $A$.
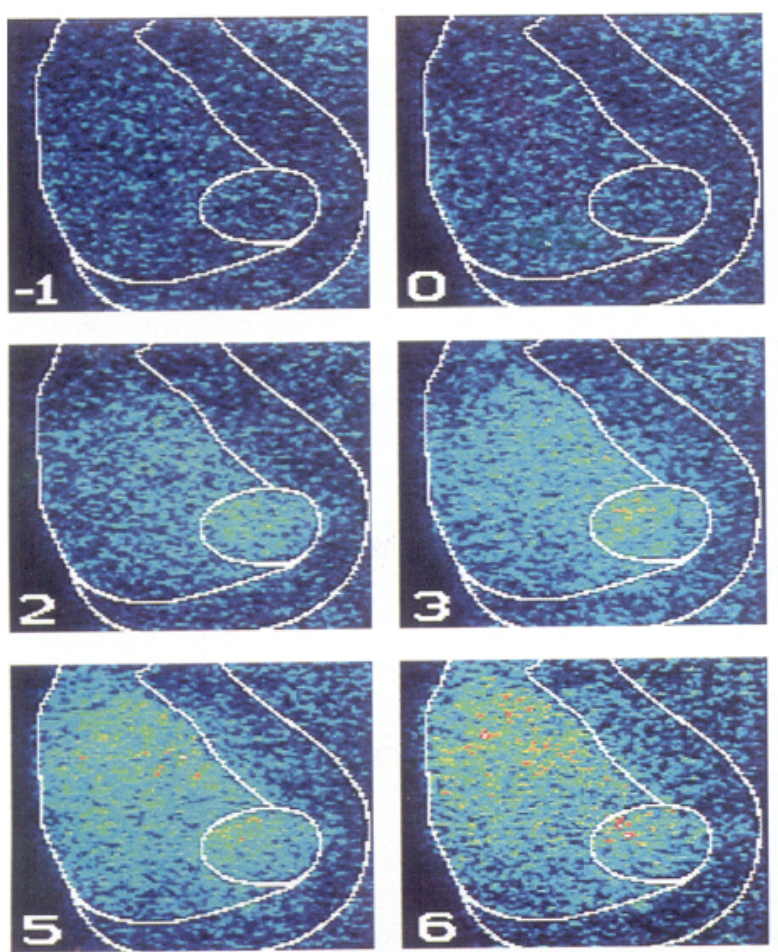

IN T. N

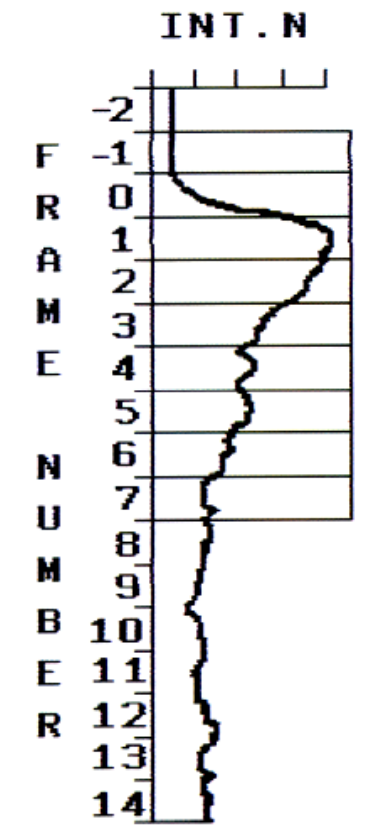

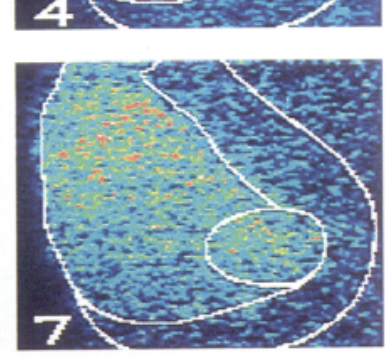

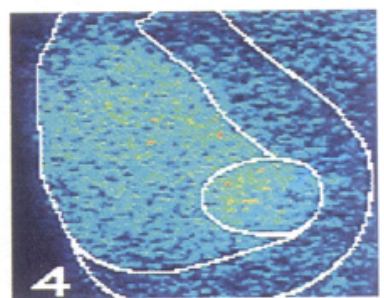

Figure 10. Optical recording of the initial activity in a transverse plane of an E11 spinal cord at the onset of spontaneous rhythmic activity. Each frame is a difference image obtained by subtracting that particular frame from a control image just before activity. began. Each frame was generated by averaging the activity from three separate spontaneous episodes, each of which was synchronized to the onset of the electrical activity. The averaged rectified, integrated neurogram from the femorotibialis muscle nerve is shown to the right of the video frames, and the time of occurrence of each frame is indicated on the abscissa. Time 0 marks the onset of the electrical activity. Scale bar (for videomicrographs), $200 \mu \mathrm{m}$. 
A
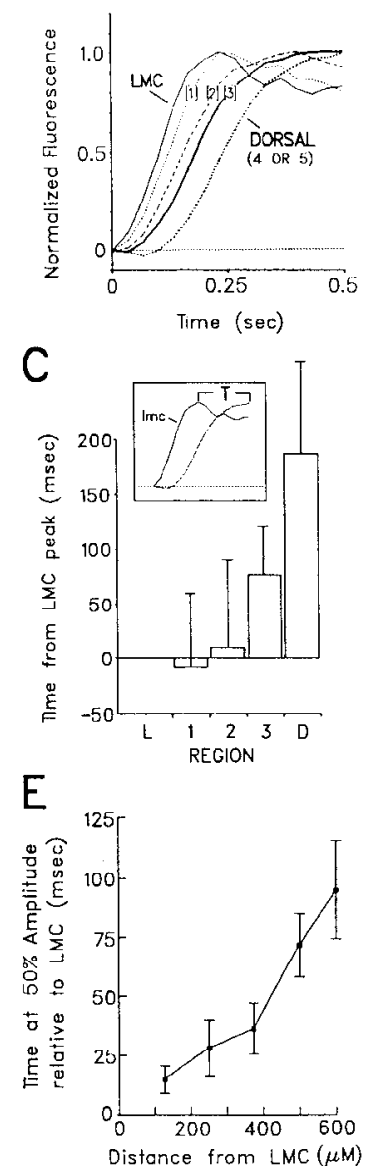

Figure 11. A, A comparison of the rise time of the normalized fluorescent transients recorded from several regions (defined in $B$ ) reveals a progressive ventrodorsal delay in the onset and time to peak of the transient. Data are from an E11 embryo. $B$, Ventrodorsal regions (100 $\mu \mathrm{m}^{2}$ ) in which the fluorescence was averaged. In most experiments measurements were made from diagonally arranged regions as shown but in some the regions were arranged vertically. $C$, The mean $(+\mathrm{SEM})$ time of peak fluorescence from the LMC peak for eight embryos. The time to peak fluorescence in the LMC has been subtracted from the time to peak fluorescence for each region to yield the time from the LMC peak ( $T$; defined in the inset). $D$, Histogram showing the average time to $50 \%$ amplitude of the transient recorded from different regions and referenced to the time of the $50 \%$ amplitude of the transient in the lateral motor column. Data are from nine embryos (mean + SEM). $E$, Plot of the mean time to $50 \%$ amplitude $( \pm$ SEM) for the different regions against the distance of the region from the LMC. The data were generated from nine experiments. In five of the experiments the regions were organized diagonally as shown in $B$. In the remaining four the regions were arranged vertically. Data were pooled from E9-E1 2 embryos.

synaptic inputs were located on the dendrites. A second potential source of error is the presence of unlabeled neurons that did not accumulate fura-2am. Fura loading is known to be age dependent (Yuste and Katz, 1991; Dani et al., 1992) and we have confirmed this in the present experiments. As a consequence some rhythmically active cells may be unlabeled. One such cell type is motoneurons, which are among the most mature neurons in the lumbar cord, which did not always load adequately with fura-2am. In addition, it appears that at least one class of interneuron may have loaded inadequately. This is a contralaterally projecting group of interneurons whose cell bodies lie close to the central canal (Ho and O'Donovan, 1991). In the present experiments we did not observe significant rhythmic activity in the medial part of the cord where the cells are located. However, when the cells are retrogradely loaded with calcium dyes, a subset of them are rhythmically active in phase with motoneuron activity (Ho and O'Donovan, 1992). Whether there are other populations of unlabeled but rhythmically active cells is unclear at present. However, several lines of evidence suggest that the distribution we have observed, with the majority of active cells in the ventrolateral part of the cord, is unlikely to be substantially altered by the existence of unloaded cells. First, the dorsal part of the cord was generally better labeled than the ventral part, in accordance with its relative immaturity in comparison to the ventral cord, but it contained fewer rhythmically active cells. Second, cell loading was improved in younger embryos, but the dorsal region still contained few rhythmically active neurons. Finally, corroborating evidence for the distribution we have observed comes from ablation studies showing that normally patterned motor output can be recorded from the ventrolateral region after it has been isolated from the rest of the spinal cord (Ho and O'Donovan, 1993).

Cells within the confines of the LMC were almost certainly motoneurons, as confirmed on some occasions by antidromic stimulation or following retrograde labeling. Outside the LMC the identity of the cells is less clear and the population could include local interneurons, ascending interneurons, propriospinal interneurons and glia. Several lines of evidence suggest that we have probably not recorded from a significant number of glial cells during rhythmic activity although we cannot exclude the possibility. Most of our recordings were made before the onset of myelination (at E13-E14; Bensted et al., 1957; Keirstead et al., 1992) or the appearance of GFAP immunofluorescence in the white matter of the spinal cord (E12; Bignami and Dahl, 1975). In addition, we did not detect signals from cells located in the white matter where developing glia are found (Bensted et al., 1957; Bignami et al., 1975). It has demonstrated recently that astrocytes in culture or organotypic slices can exhibit glutamate- or activity-induced calcium oscillations (Cornell-Bell et al., 1990; Jensen and Chui, 1990). However, these oscillations are at a much lower frequency than those observed during episodes of rhythmic activity generated by the spinal cord. Moreover, in organotypic hippocampal slices neural stimulation results in calcium elevations in glia that are delayed from the neural responses by several seconds (Dani et al., 1992). We observed no such delayed responses following rhythmic activity and found instead that all of the active cells exhibited fluorescence transients that were tightly synchronized with other cells in the population and with motoneuron discharge. Finally, direct confirmation of the identity and dynamics of interneurons has been accomplished by backfilling their axons with calcium green dextran (Ho and O'Donovan, 1992). The location and behavior of these cells are similar to that of the fura-2am-loaded cells reported here.

\section{Ventrolateral origin of spreading fluorescence activity}

The observation that activity can begin in the ventral part of the cord and migrate dorsomedially surprised us. This type of spreading activity has not been described before in the spinal cord. Moreover, in a number of experiments activity peaked in the LMC before other regions. This observation raises the possibility that motoneurons might play some role in generating the rhythm. Such a conclusion would be consistent with earlier ablation experiments revealing that rhythmic motoneuron ac- 

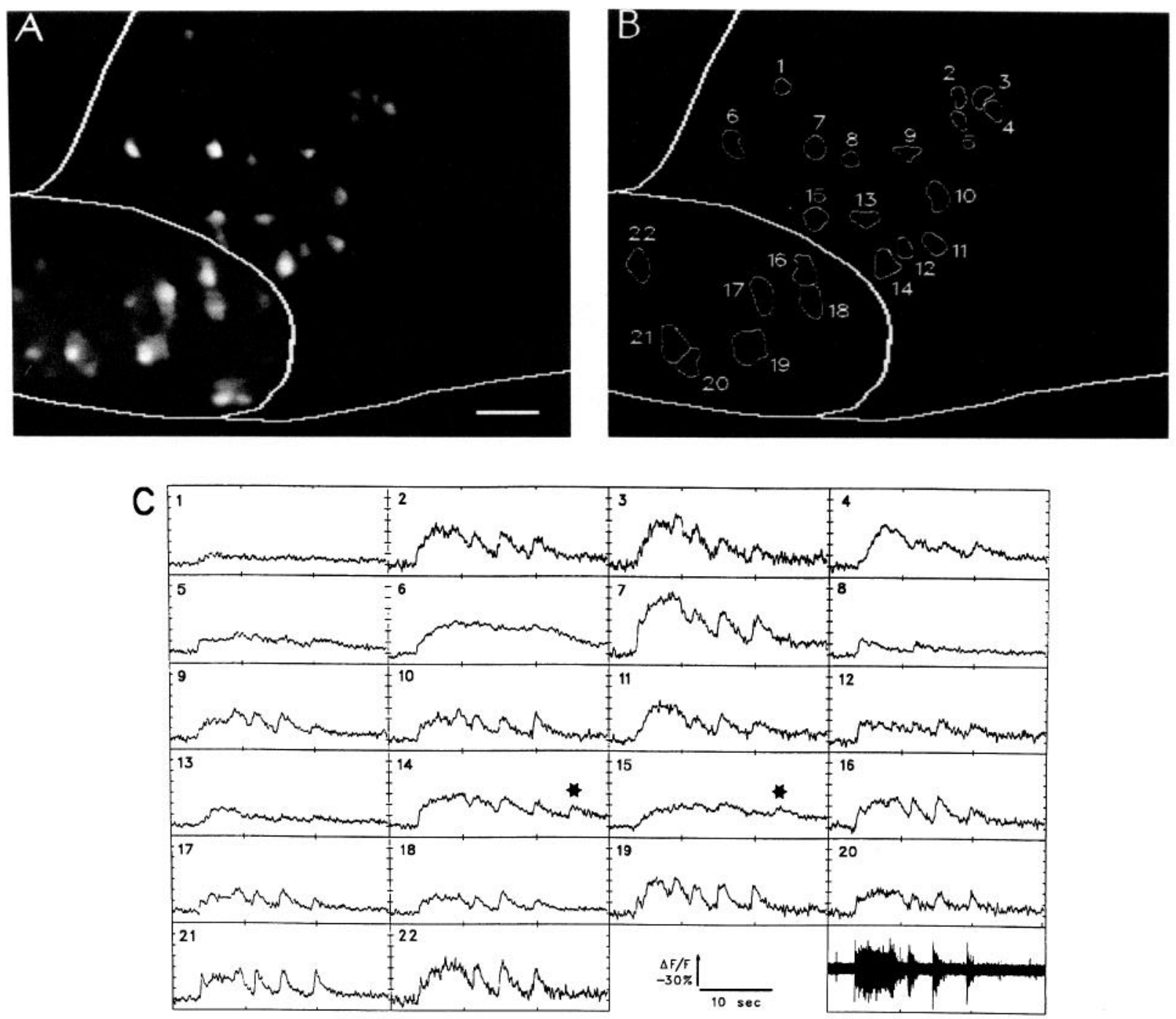

Figure 12. Intracellular calcium transients are synchronized in different neurons during each cycle of rhythmic activity. $A$, Difference image of the region around the LMC showing the cells that were activated during an episode of rhythmic activity. The optical recordings were made from the rostral face of the spinal cord transected between the third and fourth lumbosacral segments, which contains femorotibialis motoneurons. The boundaries of the gray matter and the LMC are outlined. The range of pixel values has been linearly expanded to occupy the full range (0-255) of the 8-bit digital frame store. $B$, Outlines of 22 of the cells shown in $A$. $C$, Video-rate measurements of the fluorescent changes in the 22 individual cells whose outlines are drawn and numbered in $B$. The bottom right panel in $C$ shows the femorotibialis muscle nerve activity displayed at the same time scale as the optical responses. Data are from an E12 embryo. Dorsal is up and lateral to the left. Scale bar (for videomicrographs, in A), $50 \mu \mathrm{m}$.

tivity persists when a ventral strip of the lumbosacral cord, including the $\mathrm{LMC}$, is completely isolated from the rest of the cord (Ho and O'Donovan, 1993). To explain the spread of the activity requires that the motoneuron activity must rhythmically excite other neurons in the cord. The only known synaptic connections of motoneurons with interneurons are those mediating recurrent inhibition (Velumian, 1984), although the present data do not allow us to exclude the possibility that developing motoneurons have other synaptic targets. It is also conceivable that rhythmically active motoneurons could excite other regions of the cord nonsynaptically through the release of $\mathrm{K}^{+}$or some other agent. This possibility seems unlikely, however, because antidromic stimulation of motoneurons generally does not excite rhythmic activity.

Another possibility, which we believe to be unlikely, is that the spreading activity is similar in mechanism to the glial cal- cium waves that have been recorded in culture or in organotypic slices because the velocity of the fluorescence spread reported here (4-10 $\mu \mathrm{m} / \mathrm{msec})$ is several orders of magnitude faster than the glial calcium waves that move between cells with a velocity of about 8-10 $\mu \mathrm{m} / \mathrm{sec}$ (Dani et al., 1991).

The mechanism we favor does not require that motoneurons are the source of the rhythm. We propose instead that motoneurons and other ventrolateral interneurons are among the first cells to be synaptically excited in the cut face, because their activation has been demonstrated to depend in part upon axons traveling in the adjacent, ventrolateral white matter (Ho and O'Donovan, 1993). Therefore, the ventrolateral spread of activity in the transverse face of the spinal cord could reflect the differential arrival of synaptic inputs from the adjacent white matter or sequential ventrodorsal and ventromedial synaptic activation of neurons in the transverse plane of the spinal cord. 


\section{Synchronization of calcium transients in motoneurons and interneurons during rhythmic activity}

One of the most striking results to emerge from this study was the widespread synchrony in the fluorescence transients of different neurons during rhythmic activity. Such synchrony is likely to result from the well-documented synchrony in the electrical activation of spinal neurons (Provine, 1971, 1972; Ripley and Provine, 1972; Ho and O'Donovan, 1993). The mechanism responsible for this coactivation of spinal neurons is probably the presence of extensive excitatory interconnections between the spinal neurons. Although we cannot exclude the possibility that the neurons are electrically coupled, this appears to be less likely because the great majority of interneurons are not dye coupled using neurobiotin as a tracer (Ritter and O'Donovan, unpublished observations).

However, it should also be emphasized that synchronized calcium transients do not necessarily imply synchronized motoneuron and interneuron discharge. Impulse-related calcium transients are comparatively slow outlasting single action potentials by several hundred milliseconds. This coupled with the low sampling rate of video $(30 \mathrm{~Hz})$ will tend to smooth the fluorescence transients associated with impulse activity and make it difficult to infer discharge patterns from the optical signals. Consistent with these observations was our failure to observe alternating optical motoneuron activity even though extensor motoneurons are known to fire during the period of flexor inhibition (O'Donovan, 1989). The inhibitory period in flexor motoneurons is short $(<0.5 \mathrm{sec}$; Landmesser and O'Donovan, 1984), so optical activity arising from the discharge immediately preceding it will decay slowly and tend to mask the inhibitory period. In addition, the flexor inhibition appears to be mediated by a depolarizing IPSP (O'Donovan, 1989; Sernagor and O'Donovan, 1991) that may be accompanied by calcium entry (see Yuste and Katz, 1991).

\section{Role of intracellular calcium elevation during rhythmic activity}

Although we have not demonstrated directly that the fluorescence transients generated during rhythmic activity are due to elevations of intracellular calcium, several observations support this idea. First, the excitation spectrum of the responses corresponds to that of the calcium-fura complex. Very small changes in fluorescence occur at excitation wavelengths of $360 \mathrm{~nm}$, suggesting that the influence of other factors is likely to be small (see Fig. 5). Second, we have demonstrated previously that the antidromic responses of motoneurons backfilled with calcium dyes are largely abolished in the absence of extracellular calcium and are depressed by calcium channel blockers (O'Donovan and Ho, 1992; O'Donovan et al., 1993).

It is likely that the elevations of intracellular calcium that accompany rhythmic activity will be associated with multiple functions in developing neurons. Fields et al. (1991) were able to show that the strength and number of synaptic connections between cultured sensory afferents and motoneurons could be increased by neural activity, and that these changes were calcium-dependent. If such a mechanism operates in the developing spinal cord it could explain the existence of synchronized calcium transients in the rhythm-generating network. The synchrony would reflect the calcium changes accompanying the action of both excitatory and inhibitory synaptic connections within the network. Rhythmic synaptic inputs to motoneurons and interneurons are synchronized and depolarizing (Ritter and
O'Donovan, unpublished observations) as they are between functionally antagonist motoneurons, despite the fact that the firing patterns of the cells are not necessarily synchronized (O'Donovan, 1989; Sernagor and O'Donovan, 1991). Excitatory synaptic potentials will be accompanied by calcium entry into the postsynaptic cell through ligand-gated channels or as a result of the synaptically induced firing. Depolarizing GABAergic or glycinergic inputs may also be accompanied by calcium entry through voltage-gated calcium channels as has been proposed for developing cortical neurons (Yuste and Katz, 1991). As such, the elevations of postsynaptic calcium would provide a common mechanism for the strengthening both inhibitory and excitatory connections within the rhythmically active network. Further experiments will be required to establish if spontaneous rhythmic activity does, in fact, result in a strengthening of the synaptic connections between neurons in the network.

\section{Comparison with other systems}

Recently, calcium imaging has been applied to slices of developing rat neocortex (Yuste et al., 1992) and a preliminary report has described its application to the developing retina (Wong et al., 1992). In the cortex groups of neurons were found to exhibit spontaneous, synchronized elevations of calcium. In contrast to the calcium transients observed in the present study, which depend on network function, the calcium elevations in the neocortex were preserved in the presence of TTX. Moreover, the synchrony between cells appeared to result from the presence of gap junctions between cortical cells. In the spinal cord, gap junctions probably do not mediate the synchrony because intracellularly injected neurobiotin is confined to a single cell in the great majority of interneurons (Ritter and O'Donovan, unpublished observations). This situation is very different from the developing neocortex where up to 70 cells can be labeled after intracellular injection of a single neuron with neurobiotin (Yuste et al., 1992). It would be of considerable interest to establish if the behavior described in the cortex can be observed in the spinal cord, earlier in development, when cells are known to be electrically coupled (Sheridan, 1968).

\section{References}

Alconero BB (1965) The nature of the earliest spontaneous activity of the chick embryo. J Embryol Exp Morphol 13:255-266.

Barry M, O'Donovan MJ (1987) The effects of excitatory amino acids and their antagonists of the generation of motor activity in the isolated chick cord. Dev Brain Res 36:271-276.

Bekoff A (1976) Ontogeny of leg motor output in the chick embryo: a neural analysis. Brain Res 106:271-291.

Bekoff A, Stein PSG, Hamburger V (1975) Coordinated motor output in the hindlimb of the 7-day-old chick embryo. Proc Natl Acad Sci USA 72:1245-1248.

Bensted JPM, Dobbing J, Morgan RS, Reid RTW, Payling Wright G(1957) Neuroglial development and myelination in the spinal cord of the chick embryo. J Embryol Exp Morphol 5:428-437.

Bignami A, Dahl D (1975) Astroglial protein in the developing spinal cord of the chick embryo. Dev Biol 44:204-209.

Birch BD, Eng DL, Koscis JD (1992) Intranuclear $\mathrm{Ca}^{2+}$ transients during neurite regeneration of an adult mammalian neuron. Proc Natl Acad Sci USA 89:7978-7982.

Cornell-Bell AH, Finkbeiner SM, Cooper MS, Smith SJ (1990) Glutamate induces calcium waves in cultured astrocytes: long-range glial signaling. Science 247:470-473.

Dani JW, Chernovsky A, Smith SJ (1992) Neuronal activity triggers calcium waves in hippocampal astrocyte networks. Neuron 8:429440.

Desarmenien MG, Spitzer NC (1991) Role of calcium and protein kinase $C$ in development of the delayed rectifier potassium current in Xenopus spinal neurons. Neuron 7:797-805. 
Fields RD, Yu C, Nelson PG (1991) Calcium, network activity and the role of NMDA channels in synaptic plasticity in vitro. J Neurosci 11:134-146.

Garner LK, Mendelson BM, Albers KM, Kindy M, Davis BM (1992) Effect of activity on enkephalin and Substance P mRNA in the developing chick spinal cord. Soc Neurosci Abstr 18:420.

Grynkiewicz G, Poenie M, Tsien R (1985) A new generation of $\mathrm{Ca}^{2+}$ indicators with greatly improved fluorescence properties. J Biol Chem 260:3440-3450.

Hamburger V (1948) The mitotic patterns in the spinal cord and their relation to histogenic processes. J Comp Neurol 88:221-284.

Hamburger V (1976) The developmental history of the motoneuron. Neurosci Res Prog Bull 15:1-37.

Hamburger V, Balaban M (1963) Observations and experiments on spontaneous rhythmical behavior in the chick embryo. Dev Biol 7:533545.

Hernadez-Cruz A, Sala F, Adams PR (1990) Subcellular calcium transients visualized by confocal microscopy in a voltage clamped vertebrate neuron. Science 247:858-862.

Ho S, O'Donovan MJ (1991) Properties of propriospinal neurons involved in the rhythmic excitation of motor pools in the isolated embryonic chick spinal cord. Soc Neurosci Abstr 17:120.

Ho S, O'Donovan MJ (1992) Optical and pharmacological studies of propriospinal neurons involved in rhythmic motor activity in the embryonic chick spinal cord. Soc Neurosci Abstr 18:1057.

Ho S, O'Donovan MJ (1993) Regionalization and inter-segmental coordination of rhythm generation networks in the spinal cord of the chick embryo. J Neurosci 13:1354-1371.

Holliday J, Spitzer NC (1990) Spontaneous calcium influx and its roles in differentiation of spinal neurons in culture. Dev Biol 141:1323.

Holliday J, Adams RJ, Sejnowski TJ, Spitzer NC (1991) Calciuminduced release of calcium regulates differentiation of cultured spinal neurons. Neuron 7:787-796.

Hollman M, Hartley M, Heinemann S (1991) $\mathrm{Ca}^{2+}$ permeability of KA-AMPA-gated glutamate receptor channels depend on subunit composition. Science 252:851-853.

Jensen AM, Chiu SY (1990) Fluorescence measurement of changes in intracellular calcium induced by excitatory amino acids in cultured cortical astrocytes. J Neurosci 10:1165-1175.

Keirstead HS, Hasan SJ, Muir GD, Steeves JD (1992) Suppression of the onset of myelination extends the permissive period for the functional repair of embryonic spinal cord. Proc Natl Acad Sci USA 89: 11664-11668.

Kudo Y, Takeda K, Hicks TP, Ogura A, Kawasaki Y (1989) A new device for monitoring concentrations of intracellular $\mathrm{Ca}^{2+}$ in $\mathrm{CNS}$ preparations and its application to the frog's spinal cord. J Neurosci Methods 30:161-168.

Landmesser L (1978) The distribution of motoneurons supplying chick hind limb muscles. J Physiol (Lond) 284:371-389.

Landmesser LT, O'Donovan MJ (1984) Activation patterns of embryonic chick hindlimb muscles recorded in-ovo and in an isolated spinal cord preparation. J Physiol (Lond) 347:189-204.

MacDermott AB, Mayer ML, Westbrook GL, Smith SJ, Barker JL (1986) NMDA-receptor activation increases cytoplasmic calcium concentration in cultured neurons. Nature 321:519-522.

McCobb DP, Beam KG (1991) Action potential voltage-clamp commands reveal striking differences in calcium entry via low and high voltage-activated channels. Neuron 7:119-127.

McCobb DP, Best PM, Beam KG (1989) Development alters the expression of calcium currents in chick limb motoneurons. Neuron 2:1633-1643.

McLennan I (1983) Neural dependence and independence of myotube production in chicken hindlimb muscles. Dev Biol 98:287-294.

Mendelson B (1992) Activity dependent alterations in substance P and CGRP immunoreactivity in neurons and fibers in the embryonic chick spinal cord. Soc Neurosci Abstr 18:420.
O'Donovan MJ (1989) Motor activity in the isolated spinal cord of the chick embryo: synaptic drive and firing pattern of single motoneurons. J Neurosci 9:943-958.

O'Donovan MJ, Ho S (1992) The role of extracellular calcium and calcium channels in activity dependent intracellular calcium changes in embryonic chick motoneurons. Soc Neurosci Abstr 18:1303.

O'Donovan MJ, Landmesser LT (1987) The development of hindlimb motor activity studied in an isolated preparation of the chick spinal cord. J Neurosci 7:3256-3264.

O'Donovan MJ, Yee W, Antal M (1990) Real time optical detection of rhythmic motoneuron and interneuron activity in the isolated spinal cord using digital imaging of calcium transients. Soc Neurosci Abstr 16:1132

O'Donovan MJ, Ho S, Yee W, Antal M (1991) Real-time imaging of identified propriospinal neuron activity following bath application of fura2-AM and microinjection of fura2-dextran into fiber tracts. Soc Neurosci Abstr 17:120.

O'Donovan MJ, Sernagor E, Sholomenko G, Ho S, Antal M, Yee W (1992) Development of spinal motor networks in the chick embryo. J Exp Zool 261:261-273.

O'Donovan MJ, Ho S, Sholomenko G, Yee W (1993) Real-time imaging of neurons retrogradely and anterogradely loaded with calcium sensitive dyes. J Neurosci Methods 46:91-106.

Ogura A, Akita K, Kudo Y (1990) Non-NMDA receptor mediates cytoplasmic $\mathrm{Ca}^{2+}$ elevation in cultured hippocampal neurons. Neurosci Res 9:103-113.

Pittman R, Oppenheim RW (1978) Neuromuscular blockade increases motoneuron survival during normal cell death in the chick embryo. Nature 271:364-366.

Pittman R, Oppenhein RW (1979) Cell death of motoneurons in the chick embryo spinal cord. IV. Evidence that a functional neuromuscular interaction is involved in the regulation of naturally occurring cell death and the stabilization by synapses. J Comp Neurol 187:425446.

Provine RR (1971) Embryonic spinal cord: synchronized spatial distribution of polyneuronal burst discharges. Brain Res 29:155-158.

Renaud D, LeDourain GH, Khaskiye A (1978) Spinal cord stimulation in chick embryo: effects on development of the posterior latissimus dorsi muscle and neuromuscular junctions. Exp Neurol 60:189-200.

Ripley KL, Provine RR (1972) Neural correlates of embryonic motility in the chick. Brain Res 45:127-134.

Sernagor E, O'Donovan MJ (1991a) Physiological and pharmacological characteristics of rhythmic excitatory and inhibitory inputs onto motoneurons in the chick embryo spinal cord. Soc Neurosci Abstr 17:120.

Sernagor E, O'Donovan MJ (1991b) Whole cell patch clamp of rhythmically active motoneurons in the isolated spinal cord of the chick embryo. Neurosci Lett 128:211-216.

Sheridan JD (1968) Electrophysiological evidence for low-resistance intercellular junctions in the early chick embryo J Cell Biol 37:650659.

Toutant JP, Toutant MN, Renaud D, Le Douarin GH (1979) Enzymatic differentiation of muscle fiber types in embryonic latissimus dorsi of the chick: effects of spinal cord stimulation. Cell Differ 8:375382.

Velumian AA (1984) Direct evidence for postsynaptic inhibition in the embryonic chick spinal cord. Exp Brain Res 14:229-239.

Wong ROL, Chernjavsky A, Smith SJ, Shatz CJ (1992) Correlated spontaneous calcium bursting in the developing retina. Soc Neurosci Abstr 18:923.

Yuste R, Katz LC (1991) Control of postsynaptic $\mathrm{Ca}^{2+}$ influx in developing neocortex by excitatory and inhibitory neurotransmitters. Neuron 6:333-344.

Yuste R, Peinado A, Katz LC (1992) Neuronal domains in developing neocortex. Science 257:665-669. 